\title{
The Price and Quantity of Residential Land in the United States*
}

\author{
By Morris A. Davis and Jonathan Heathcote \\ Federal Reserve Board of Governors and Georgetown University ${ }^{1}$
}

We combine publicly available data from Freddie Mac, the Decennial Census of Housing, and the Bureau of Economic Analysis to construct the first constant-quality aggregate price index for the stock of residential land in the United States. We uncover five main results: (a) since 1970, residential land prices have grown faster but (b) have also been twice as volatile as existing home prices; (c) averaged from 1970 to 2003, the nominal stock of residential land under 1-4 unit structures accounts for $38 \%$ of the market value of the housing stock and is equal to $50 \%$ of nominal annual GDP; (d) the real stock of residential land under 1-4 unit structures has increased an average of $0.6 \%$ per year since 1970; and (e) residential investment leads the price of residential land by three quarters. We also estimate that in 2003:Q3 the nominal value of the entire stock of residential land is the same as annual GDP. Finally, we show for the US data that the logarithms of the nominal price index for residential land, disposable income, and interest rates are cointegrated.

*This version: July, 2004.

${ }^{1}$ The authors thank Bradford Case, Amy Crews Cutts, Christopher Downing, Josh Gallin, Jim Kennedy, Andreas Lehnert, Tom Liddle, Rob Martin, Randal Matsunaga, Kevin Moore, Stephen Oliner, Michael Palumbo, Peter Rupert, and others for comments and suggestions. The opinions expressed here are those of the authors and not necessarily those of the Board of Governors of the Federal Reserve System or its staff. Please address correspondence to Morris Davis, Federal Reserve Board, mail stop 97, 20th and C Streets NW, Washington DC 20551, USA. Tel: 202 452-3628. Fax: 202 728-5889. Email: Morris.A.Davis@frb.gov. 


\section{Introduction}

Over the past five years, the cumulative real rate of appreciation in the value of existing homes in many metro areas of the United States has been at or near historic highs. This can be seen in Figure 1, which graphs the real (inflation-adjusted) 5-year cumulative growth of home prices for various major primary Metropolitan Statistical Areas (MSAs). Figure 1 quite clearly shows that many MSAs experienced a decline in real house prices in the five year period starting in 1990 and ending in $1995 .^{2}$ Of primary concern to some analysts is whether the recent run-up in aggregate home prices will be somewhat reversed, much like the the 1985-90 and 1990-95 experience.

In this paper, we explore one possible source of booms and busts in home prices, fluctuations in residential land prices. A house can be viewed as a composite of two pieces: A perfectly reproducible structure and an irreproducible component that we call "Land." Land refers not only to the square footage of the property, but also to amenities, intangible attributes such as the length of the commute to work. Our method for constructing a constant-quality price index for residential land is based on the observation that the growth rate of the price of a home is a weighted average of the growth rate of the replacement cost of the structure and the growth rate of the price of the land that is attached. For the United States, the growth rates of house prices and structures costs are publicly available. We construct appropriate weights to back out an implicit price index for residential land. Our procedure simultaneously yields an estimate of the real stock of residential land. This estimate is not simply a measure of acreage, just as the real stock of computers is not mea-

\footnotetext{
${ }^{2}$ Many MSAs also experienced a nominal decline in house prices in this same time period (not shown). For example, the Los Angeles CMHPI has a value of 169.12 in the third quarter of 1990. The CMHPI for Los Angeles started to decline in 1990:Q4 and did not achieve a value of 169.68 until the fourth quarter of 1999.
} 
sured by the number of PC boxes. Rather, each unit of land is an amalgam of square-footage and amenities.

Our main findings concerning the measurement of land prices and quantities are as follows. First, since 1983, the price of land has been growing much more quickly than the price of existing homes. Second, the real quality-adjusted price of land is about twice as volatile as both real disposable income and the inflation-adjusted price index for existing homes. Third, we find that when averaged from 1970 to 2003, the nominal value of residential land under 1-4 unit structures accounts for $38 \%$ of the market value of those homes and is about equal to $50 \%$ of annual GDP. Fourth, we show that the growth rate of the real stock of residential land under 1-4 unit structures is very low, $0.6 \%$ per year on average. Finally, measured at business cycle frequencies, real residential investment leads real residential land prices by three quarters.

Note that one of the key pieces of publicly available data we use to infer the price of land, the price index for existing homes, is most appropriate for 1-4 unit structures. This explains why we focus on land attached to 1-4 unit structures throughout our analysis. Data from the 2000 Decennial Census of Housing suggest that the market value of the 1-4 unit housing stock accounts for $70 \%$ of the market value of the entire residential stock. If the nominal value of residential land under 1-4 unit structures is also approximately equal to $70 \%$ of the total nominal value of residential land in the United States, then we find that in 2003:Q3, the nominal value of the entire stock of residential land is the same as annual GDP.

We also show that the logarithm of the nominal price index for residential land is likely cointegrated with the logarithms of nominal disposable personal income and the nominal 3-month Treasury Bill. That is, long-term movements to the price of residential land appear to be largely mirrored by proportional movements to nominal disposable personal income and interest rates. In contrast, the replacement cost of structures should be tied to the cost 
of construction inputs and the underlying productivity of capital and labor used to build new residential structures, as in Davis and Heathcote (2003). This is because the structure is perfectly reproducible using a known technology. Thus, the structures component of the growth rate of house prices is a relatively smoothly growing and perhaps partially predictable series while the price of quality-adjusted land is not pinned down by production technologies (for example, there is no production technology to build more land in Los Angeles that has both a view of the ocean and a fifteen minute drive to downtown).

The rest of this paper proceeds as follows. In the next section, we document our procedure for constructing a constant-quality price index for residential land. In section 3 we briefly discuss key measurement issues, relegating many details to the Appendix. In section 4 we analyze the properties of our residential land price and quantity series, and section 5 concludes.

\section{Accounting}

In any period $t$, define the nominal market value of the home $\left(p_{t}^{h} h_{t}\right)$ as the sum of the nominal replacement cost of the physical structures $\left(p_{t}^{s} s_{t}\right)$ and the nominal value of the residential land $\left(p_{t}^{l} l_{t}\right)$,

$$
p_{t}^{h} h_{t}=p_{t}^{s} s_{t}+p_{t}^{l} l_{t} .
$$

In the above equation, $p_{t}^{h}, p_{t}^{s}$, and $p_{t}^{l}$ are the quality-adjusted relative price-per-unit in period $t$ of a home, physical structure, and land and amenities (hereafter called "land") and $h_{t}, s_{t}$, and $l_{t}$ are the quality-adjusted real quantities.

To derive a price index for residential land, our key assumption is

$$
\left(\frac{p_{t+1}^{h}}{p_{t}^{h}}\right) p_{t}^{h} h_{t}=\left(\frac{p_{t+1}^{s}}{p_{t}^{s}}\right) p_{t}^{s} s_{t}+\left(\frac{p_{t+1}^{l}}{p_{t}^{l}}\right) p_{t}^{l} l_{t} .
$$


Stated in words, equation (2) imposes that if the nominal stock of structures and the nominal stock of land are revalued between $t$ and $t+1$, then the housing stock is also appropriately revalued between $t$ and $t+1$. The relationship linking growth in existing home prices to growth in structures costs and land prices,

$$
\left(\frac{p_{t+1}^{h}}{p_{t}^{h}}\right)=\left(\frac{p_{t+1}^{s}}{p_{t}^{s}}\right) \frac{p_{t}^{s} s_{t}}{p_{t}^{h} h_{t}}+\left(\frac{p_{t+1}^{l}}{p_{t}^{l}}\right) \frac{p_{t}^{l} l_{t}}{p_{t}^{h} h_{t}},
$$

directly follows from (2). Equation (3) expresses the growth rate of existing home prices as the weighted average of the growth rate in structures prices and the growth rate of land prices. The structures weight is the fraction of market value accounted for by the replacement cost of structures. By equation (1), the land weight is one minus the structures weight.

Equation (3) implies that complete time series for the market value of homes, replacement cost of structures, and market value of land are needed to construct a price index for land. We construct these time series using the following perpetual inventory systems,

$$
\begin{aligned}
p_{t+1}^{h} h_{t+1} & =\left(\frac{p_{t+1}^{h}}{p_{t}^{h}}\right) p_{t}^{h} h_{t}+p_{t+1}^{h} \Delta h_{t+1} \\
p_{t+1}^{s} s_{t+1} & =\left(\frac{p_{t+1}^{s}}{p_{t}^{s}}\right) p_{t}^{s} s_{t}+p_{t+1}^{s} \Delta s_{t+1} \\
p_{t+1}^{l} l_{t+1} & =\left(\frac{p_{t+1}^{l}}{p_{t}^{l}}\right) p_{t}^{l} l_{t}+p_{t+1}^{l} \Delta l_{t+1},
\end{aligned}
$$

where $p_{t+1}^{h} \Delta h_{t+1}, p_{t+1}^{s} \Delta s_{t+1}$, and $p_{t+1}^{l} \Delta l_{t+1}$ are the nominal net new additions to houses, structures, and land, respectively in period $t+1$. Note that equations (1) and (2) imply that $p_{t+1}^{h} \Delta h_{t+1}$ in equation (4) may be replaced with the sum of $p_{t+1}^{s} \Delta s_{t+1}$ and $p_{t+1}^{l} \Delta l_{t+1}$, i.e.

$$
p_{t+1}^{h} h_{t+1}=\left(\frac{p_{t+1}^{h}}{p_{t}^{h}}\right) p_{t}^{h} h_{t}+p_{t+1}^{s} \Delta s_{t+1}+p_{t+1}^{l} \Delta l_{t+1} .
$$

Equations (7), (5), and (6) embed the following logic: Next period's nominal value of asset $x$ must be equal to the current period's nominal value, revalued for any price changes, plus 
any net new additions. The net new additions are assumed to be purchased at next period's prices. Further, the equations impose, as we would want them to, that the real number of units of the stock of $x$ can be linearly added over time.

\section{Measurement}

It is convenient to rewrite equation (3) such that the growth rate of quality-adjusted land prices is the dependent variable, i.e.

$$
\left(\frac{p_{t+1}^{l}}{p_{t}^{l}}\right)=\left(\frac{p_{t+1}^{h}}{p_{t}^{h}}\right) \frac{p_{t}^{h} h_{t}}{p_{t}^{h} h_{t}-p_{t}^{s} s_{t}}-\left(\frac{p_{t+1}^{s}}{p_{t}^{s}}\right) \frac{p_{t}^{s} s_{t}}{p_{t}^{h} h_{t}-p_{t}^{s} s_{t}} .
$$

We construct quarterly proxies using publicly available data for all of the right-hand-side variables of this equation for the entire universe of homes (owned, rented, and vacant) in 1-4 unit structures in the United States. ${ }^{3}$ Starting with $\left(p_{t+1}^{h} / p_{t}^{h}\right)$, we estimate the quarterly nominal growth rate of existing home prices in the United States using the aggregate "Conventional Mortgage Home Price Index" (CMHPI) series published by Freddie Mac, which

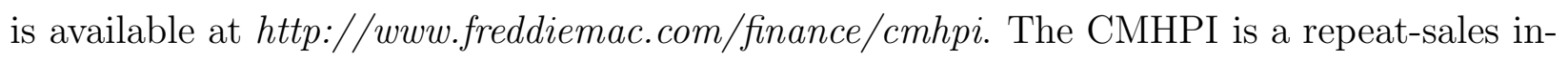
dex that samples from the aggregate stock of homes in single-family attached and detached structures, and it has the potential to capture growth in home prices from period $t-1$ to $t$ holding the real units of aggregate housing fixed at its $t-1$ level. ${ }^{4}$ In our analysis, we assume

\footnotetext{
${ }^{3}$ The universe of 1-4 unit structures includes the entire stock of single-family detached and attached housing units as well as housing units in 2-4 family buildings.

${ }^{4}$ The CMHPI is not a perfect measure for the growth in aggregate home prices to be used in equation (8). As noted, the CMHPI does not include data from multiple-unit (2-4) structures. Further, the CMHPI treats home appraisals conducted before mortgage refinancing equivalently to sales data. Finally, to be included in the CMHPI calculations, a house must have been transacted or appraised at least twice, and the first mortgage on the house must have been conforming both times.
} 
the growth rate of prices for the entire 1-4 unit stock (including homes in 2-4 unit buildings) is captured by the CMHPI. We focus on homes in 1-4 unit buildings since these are the homes most likely to be in the CMHPI for which both replacement cost and market-value data exist. As noted in the introduction, data from the 2000 Decennial Census of Housing suggests the 1-4 unit stock accounts for $70 \%$ of the market value of all residential structures in the United States.

Next, we estimate the growth rate of the replacement cost of structures for the United States $\left(p_{t+1}^{s} / p_{t}^{s}\right)$ by slightly modifying the quarterly price index for gross investment in 14 unit structures as published by the Bureau of Economic Analysis (BEA) in the National Income and Product Accounts (NIPA). The NIPA data are available on the BEA's web site at www.bea.doc.gov. ${ }^{5}$ The BEA also publishes end-of-year estimates of the real $\left(s_{t}\right)$ and nominal $\left(p_{t}^{s} s_{t}\right)$ replacement cost of structures in 1-4 unit structures in their Detailed Residential Fixed Asset Tables, also available on the BEA's web site. ${ }^{6}$ We construct a quarterly estimate of the replacement cost of structures using the perpetual inventory method of equation (5), the series for the growth of structures prices $\left(p_{t+1}^{s} / p_{t}^{s}\right)$, and quarterly data on the gross investment in structures provided in the tables in Section 5 of the NIPA.

Finally, we construct series for nominal net new investment in land and structures and use the accounting identity of equation (7) (along with data from the 2000 Decennial Census

\footnotetext{
${ }^{5}$ Confusingly, gross investment in 1-4 unit structures in the NIPA (not including improvements to existing structures) is labeled as investment in "permanent-site single-family residential structures." To download the data, click on the Gross Domestic Product link, then click on Interactive NIPA tables, and then List of all NIPA Tables. The price index for permanent-site single-family residential structures is available in table 5.3.4.

${ }^{6}$ From the BEA's home page, click on Fixed Assets and then Detailed Fixed Assets Tables.
} 
of Housing) to build a time series of the market value of 1-4 unit structures $p_{t}^{h} h_{t} \cdot{ }^{7}$ We identify nominal net investment in structures in period $t+1, p_{t+1}^{s} \Delta s_{t+1}$, as the nominal value of structures at quarter $t+1$ less the nominal value of structures at quarter $t$, revalued for any price changes. Nominal net new investment in land in period $t+1, p_{t+1}^{l} \Delta l_{t+1}$, is set to a roughly constant fraction of nominal gross investment in permanent-site singlefamily residential structures. Our estimate of new land is consistent with assumptions used by the Census to infer the value of new structures from data on the sales price of new homes. In particular, the Census estimates value-put-in-place by subtracting an estimate of the cost of the raw land, marketing costs, and other costs from survey data on the sales price of homes. We impute the value of new land consistently with these Census calculations. Finally, we benchmark the aggregate market value of the stock of homes in 1-4 unit buildings to $\$ 13.41$ trillion for 2000:Q2, an estimate constructed from self-reported home values from the 2000 Decennial Census of Housing available on the IPUMS web site, http://www.ipums.umn.edu/usa/index.html. ${ }^{8}$

We discuss in detail the construction of all of our series in Appendix A and discuss the sensitivity of our price and quantity series to key assumptions in Appendix B, but we should highlight two minor alterations we make to published data. First, we slightly smooth the published CMHPI to eliminate noise in the quarter-to-quarter growth rates. More importantly, we purge all expenditures on real estate commissions from the BEA's estimate of gross investment in residential structures. Since 1970, nominal expenditures on

\footnotetext{
${ }^{7}$ The Flow of Funds (FoF) Accounts, produced by the Federal Reserve, publishes a quarterly time series for the market value of homes. We do not use this data for reasons discussed in Appendix B.

${ }^{8}$ The IPUMS ("Integrated Public Use Microdata Series") web site, sponsored by the Minnesota Population Center at the University of Minnesota, has made available for public use Census microdata going back to 1850 .
} 
commissions have accounted for an average of $12 \%$ of published nominal gross investment in the 1-4 stock. ${ }^{9}$ Since commissions are classified by the BEA as gross investment, they also contribute by construction to the BEA's estimate of the replacement cost of structures. In our opinion, commissions should not be included in the replacement cost of structures: If a house transacts three times in one year, the cost of rebuilding that house should not automatically increase by $18 \%$ that year. Therefore, we construct a stock of commissions using perpetual inventory accounting on the NIPA commissions data and then purge this estimate from the BEA's published replacement cost series. ${ }^{10}$ We find that since 1970, the nominal stock of commissions accounts for approximately $10 \%$ of the published replacement cost of 1-4 unit structures; see Figure 2.

As a test of the accuracy of our assumptions and methods, we compare the predicted market value of homes in 1-4 unit structures for 1980 and 1990, calculated via equation (7) and benchmarked exclusively to the 2000 Census, to the aggregate market value of homes for 1980 and 1990 when calculated using data from the 1980 and 1990 Decennial Census of Housing. ${ }^{11}$ In 1990, we underpredict the market value relative to the Decennial Census by $13 \%$ but in 1980 we only underpredict by $6 \% .{ }^{12}$ We view this miss of $6 \%$ over a twenty-year

\footnotetext{
${ }^{9}$ This statistic is calculated as the average ratio, from 1970 to 2001, of published nominal gross expenditures on commissions (published in the NIPA) to the sum of nominal gross investment in additions and alterations, major repairs and replacements, and new structures for 1-4 unit structures.

${ }^{10}$ Details on our procedure to construct the stock of commissions are in Appendix A.

${ }^{11}$ Similar to the 2000 data, the micro data from the 1980 and 1990 Decennial Census of Housing are also available on the IPUMS web site.

${ }^{12}$ In 1990:Q2, our predicted market value is $\$ 7,603$ billion compared to $\$ 8,740$ billion when calculated using the 1990 Census; in 1980:Q2, our predicted market value is $\$ 3,899$ billion whereas Census calculations suggest a market value of $\$ 4,149$ billion.
} 
period as broadly vindicating our methodology.

\section{Analysis}

\subsection{Price Indexes for Land, Existing Homes, and Structures}

In Figure 3 we graph our price index for residential land and compare it to the published price indexes for existing homes and the replacement cost of structures. These panels plot the price indexes, after adjusting for changes in consumer prices, for residential land (solid line), existing homes (short-dashed line), and the replacement cost of structures (long-dashed line). ${ }^{13}$ In nominal terms, land prices have increased by a factor of 10.4 since 1970; after accounting for inflation, land prices have increased by a factor of 2.6. For comparison, inflation-adjusted (real) existing home prices have increased $69 \%$ and real structures prices have only increased $28 \%$. The remaining three panels show the major time periods where gains and losses for each series have occurred; the top-right panel shows these series from 1970:Q1 to 1982:Q4; the bottom-left from 1983:Q1 to 1995:Q4; and, the bottom-right from 1996:Q1 to 2003:Q3. From 1970 to 1982, the replacement cost series outpaced the price index for existing homes, implying that the price of land had to fall over the same period; in fact, over these 12 years, we find the real price of land cumulatively fell over $7 \%$ whereas real replacement costs increased about 26\%. In contrast, from 1982 through the end of 1995, real replacement costs cumulatively declined over $9 \%$ and real land prices cumulatively increased 55\%, although real land prices remained about flat from 1989 through 1995. Since 1996,

\footnotetext{
${ }^{13}$ All of our price indexes are end-of-quarter measures with base year of 1996. In this work and the work that follows, we convert the NIPA core consumption price index (a middle-of-quarter measure) to an endof-quarter measure by using the geometric mean of the published NIPA data for the current and subsequent quarter.
} 
real (inflation-adjusted) home prices have increased $37 \%$ but replacement costs have only increased $12 \%$ over the same time period. Land prices must be the source of the increase: We find that over this period, the inflation-adjusted constant-quality price of residential land increased $82 \%$.

Our exact estimate of the growth rate of residential land prices is derived from our estimates of land's share of the market value of homes (see equation (3)). In the top panel of Figure 4, we plot our estimate of land's share. When averaged from 1970:Q1 to 2003:Q3, the nominal value of land accounts for $38 \%$ of the nominal market value of homes. In the third quarter of 2003, we estimate land's share to be $46 \%$, its highest recorded value. In terms of current dollars, in 2003:Q3 we estimate the market value of homes in 1-4 unit structures to be $\$ 17.0$ trillion, of which $\$ 7.8$ trillion is residential land and the remaining $\$ 9.2$ trillion is the replacement cost of structures. The bottom panel of Figure 4 plots the ratio (and its average value) of the nominal value of residential land under 1-4 unit structures to nominal GDP, providing another perspective on the relative size of the nominal stock of this land. We find that over this time period, the market value of land under 1-4 unit structures averages about 50\% of nominal GDP. In 2003:Q3, the nominal value of this residential land is equal to $71 \%$ of GDP. If we assume that, analogously to the market value of homes, residential land under 1-4 unit structures accounts for 70\% of all residential land, then in 2003:Q3 the value of residential land in the United States is approximately equal to GDP. ${ }^{14}$

\footnotetext{
${ }^{14}$ The accuracy of this calculation can be assessed by looking at year 2000 data when both market value and structures replacement cost data exist for the entire stock of housing. According to our calculations from the Decennial Census of Housing (see Table 5) the market value of all residential structures in 2000 is $\$ 18.4$ trillion. Data from the Detailed Residential Fixed Asset Tables suggests that the replacement cost of all residential structures (excluding the reported stock of residential equipment and our estimate of the stock of commissions) at year-end 2000 is $\$ 9.2$ trillion. The value of the entire stock of residential land in 2000 is therefore about $\$ 9.2$ trillion; nominal GDP in 2000 was $\$ 10.0$ trillion. Note that this calculation
} 


\subsection{Price Index for Land and Farm Price-Per-Acre}

Figure 5 compares our land-price series to the price-per-acre of farm land for the aggregate United States. This farm price-per-acre series, available from the United States Department

of Agriculture web site ${ }^{15}$ is the only other published aggregate price series for land in the United States of which we are aware. The four panels of this Figure plot the two series after adjusting for consumer price inflation. The top-left panel plots the series for the entire sample and the other three panels plot the two series for three subsamples. From 1970 to 1982 the inflation-adjusted price-per-acre of farm land increased $89 \%$ while the price of residential land fell. Conversely, from 1983-95 the inflation-adjusted price of farm land fell $34 \%$ at the same time that real residential land prices increased rapidly. Since 1996, farm land prices have increased at a much slower rate than residential land. Summarizing these graphs, movements to the real aggregate price-per-acre of farm land appear to be largely unrelated to changes to the real aggregate price of residential land.

\subsection{Nominal and Real Stock of Land}

In Figure 6, we plot the nominal and real stock of residential land under 1-4 unit structures that arises from our methods. The nominal value of this stock of land (solid line, top panel) has grown by a factor of 12.7 since 1970. However, this growth is apparently due to price appreciation and not to significant additions to the residential real stock. We find that the

suggests that in 2000 , land accounted for $50 \%$ of the total nominal value of homes, compared to our estimate of $41 \%$ for the land associated with 1-4 unit structures. Our interpretation is that $5+$ unit structures are more land-intensive than 1-4 unit structures.

${ }^{15}$ The annual data are available at http://www.ers.usda.gov/Briefing/LandUse/aglandvaluechapter.htm. We linearly interpolate the annual data to generate a quarterly price-per-acre series. 
real stock of this residential land (dashed-line, top panel) is not growing very fast; in fact, shown in the bottom panel, the average growth rate of the real stock of land is $0.6 \%$ per year. This is about 3/4 percentage point per year lower than population growth. ${ }^{16}$ For comparison, the real stock of 1-4 unit structures has been growing at $2.5 \%$ per year since 1970 (not shown).

\subsection{Business Cycle Properties of Price Index for Land}

In the spirit of Cooley and Prescott (1995), Table 1 quantifies some interesting statistical properties at business-cycle frequencies of our price index for residential land. This table documents the relative volatility and comovement of land prices with real GDP, real disposable personal income (DPI), real gross residential investment (RES), and the inflation-adjusted price of existing homes and replacement cost of structures. ${ }^{17}$ Real GDP, DPI, and RES are taken directly from the NIPA and are measured as flows throughout the quarter. All the price series, including the price index for core consumption goods, are measured at the end of the quarter. All variables have been logged and HP-filtered with parameter $\lambda=1600 .{ }^{18}$

The first column in Table 1 reports the percentage standard deviations of the detrended row variables and the second column lists the ratio of the percentage standard deviation of the price of land to the standard deviation of each listed variable. The remaining nine columns show the correlation of the detrended row variable $X$ at quarter $t-s$ with the detrended relative price of residential land at quarter $t$. For example $\operatorname{corr}\left(G D P_{t-1}, p_{t}^{l} / p_{t}^{c}\right)=$

\footnotetext{
${ }^{16}$ According to data from the US Census, the growth of the non-institutionalized population, aged 16 and older, has been $1.35 \%$ per year since 1970 .

${ }^{17}$ We report real gross residential investment rather than real gross investment in permanent-site singlefamily structures to facilitate comparison with Cooley and Prescott (1995) and similar studies.

${ }^{18}$ For more details, see the footnotes to Table 1.
} 
0.59 means that the correlation of real GDP at quarter $t-1$ with the detrended relative price of land at quarter $t$ is 0.59 . We say a variable $\mathrm{X}$ leads the relative price of land if $\operatorname{corr}\left(X_{t-s}, p_{t}^{l} / p_{t}^{c}\right)>\operatorname{corr}\left(X_{t}, p_{t}^{l} / p_{t}^{c}\right)$ for at least one $s>0$. Analogously, variable $\mathrm{X}$ lags the relative price of land if $\operatorname{corr}\left(X_{t+s}, p_{t}^{l} / p_{t}^{c}\right)>\operatorname{corr}\left(X_{t}, p_{t}^{l} / p_{t}^{c}\right)$ for at least one $s>0$.

From Table 1, we derive four facts about the relationships between output, residential investment, and the price of houses, structures, and residential land at business-cycle frequencies. First, real land prices are less volatile than real residential investment, but are more volatile than real GDP, real disposable income, real existing home prices, and the real replacement cost of structures. Strikingly, real residential land prices are more than twice as volatile as real disposable income. Second, real land prices are very highly contemporaneously correlated (a correlation of 0.87 ) with real existing home prices. Third, the inflation-adjusted replacement cost of structures appears to lag real land prices by three quarters. Finally, residential investment leads the price of land by three quarters.

This last fact may be incompatible with current theories about the causal relationship between residential investment and house prices. As noted in Davis and Heathcote (2003), many leading models of residential investment such as Topel and Rosen (1988) or Poterba (1984 and 1991) work as follows: A shock to demand affects house prices, and in response, developers build more houses along a rising marginal cost curve until the marginal cost of an additional unit of new housing equals the market price. If a shock to demand and thus house prices implies that the price of residential land increases, then according to these theories, land prices should lead and not lag residential investment. The data suggest that the opposite is true. 


\subsection{Correlates of the Price Index for Land}

In Figure 7, we plot the cumulative 5-year nominal (top panel) and real (bottom panel) returns to residential land, homes, and replacement costs. ${ }^{19}$ These panels quite clearly illustrate the boom-bust nature of home and land prices that have been a feature of the data for the past 30 years. Of the $2-1 / 2$ cycles we have experienced, in both nominal and real terms, peaks and troughs are spaced roughly 5 years apart and the difference in cumulative percentage growth from peak to trough is quite large. For example, referring to the solid line in the bottom panel, in the 5 years leading up to 1989:Q3, the price of residential land appreciated in real terms by $46 \%$ but by the next trough (1994:Q4), in real terms the price of residential land declined cumulatively by more than $9 \%$. Based solely on looking at the panels of Figure 7, if we were to speculate on the timing and size of the next trough, we would guess that land prices might not decline in nominal terms but may cumulatively decline in real terms by roughly $10 \%$ in the next three to five years.

Our goal in this section is to find a set of meaningful variables that closely move with land prices to help economists develop theoretical models to explain the boom-bust nature of land prices, and, better forecast future movements to land (and by extension) home prices. Our strategy is to look for a small set of variables that move closely with the price of residential land, and then ask what a simple statistical model based on these variables would predict for the future of land prices.

Of a set of simple models that we have explored, one that seems to perform reasonably well over history links the logarithm of the nominal price index for residential land to the logarithms of nominal disposable personal income and the beginning-of-quarter nominal

\footnotetext{
${ }^{19}$ For example, cumulative growth in nominal land prices from 1998:Q4 to 2003:Q3 was 72.7\%, which is graphed in the top panel at point 2003:Q3.
} 
three-month T-bill rate (effective annual yield). Estimation results are reported in the top box of Table 2. We use the Stock-Watson procedure to estimate the coefficients; that is, we include two leads and lags of the first-difference of the three variables as extra regressors. As shown in the top panel of Table 2, we find the elasticity of land prices with respect to income is 0.92 and the interest elasticity is -0.19 . Further, both coefficients are significantly different from zero. Interestingly enough, (not shown in Table 2) these results do not hold when the logarithm of the price index for existing homes is regressed on the logarithms of nominal disposable personal income and the nominal three-month T-bill rate: The interest rate is insignificantly related to the price index of existing homes after controlling for income. We believe this result occurs because regression analysis suggests that structures prices are positively correlated with interest rates after controlling for income.

In the bottom box of Table 2 we report the results of four different unit-root tests for the errors that result from this Model. The errors are calculated as $\log \left(p_{t}^{l}\right)-\beta_{0}-\beta_{1} \log \left(y_{t}\right)-$ $\beta_{2} \log \left(r_{t}\right)$, where $\beta_{1}$ and $\beta_{2}$ are the the reported coefficients in the top box of Table 2 and $\beta_{0}$ sets the average value of the errors for the whole sample to 0. According to these tests and a separate Johanssen test (not reported), the variables are cointegrated. Visual inspection of the time series of model errors graphed in the top panel of Figure 8 supports the hypothesis that the model error might be mean-reverting, as suggested by the unit-root tests. The error can be interpreted as the percentage gap of the price of land as predicted by the simple statistical model and the realized price of land. Except for the very early 1970's, this miss has hovered between negative and positive 10\%. As of 2003:Q3, the miss is $-2.0 \%$, about $\$ 150$ billion in nominal land value.

Although the model error may be stationary, the model does not predict very well the time-series path of nominal 5-year cumulative growth rates. The bottom panel of Figure 8 plots the actual and predicted 5-year cumulative growth of land prices. In light of the 
persistence of the model's error terms, perhaps it is not surprising the the model cannot perfectly track cumulative growth rates. The model fails at predicting the relatively low cumulative growth experienced in the five years leading up to 1975:Q1, a fact that is probably related to the extremely high miss of the model for land prices in 1970:Q1 (top panel). However, a case can be made that the model gets the contour of 5-year nominal cumulative growth right, perhaps with the timing a few years off, in the 1980-85, 1985-90, and 1990-95 periods. Further, the model seems to have been able to account for the tremendous 5-year nominal appreciation in land prices ending in 2003:Q3.

In terms of forecasting the price of residential land, the model predicts that the future price of land will move with changes to interest rates, incomes, and its own error. To illustrate how a forecast could be constructed with our model, we forecast the cumulative growth of land prices from the start of 2004 until the end of 2006 using private-sector forecasts of nominal disposable personal income and interest rates as of March, 2004. Starting with income prospects, private sector forecasters (Blue Chip) were predicting approximately a 5.6\% increase in nominal disposable income during 2004. If this same growth is forecasted to apply to 2005 and 2006, income will cumulatively grow by $17.8 \%$ from the start of 2004 through the end of 2006. Based on this forecast, holding interest rates and the model error constant, the statistical model suggests that land prices will increase by $0.92 *[\log (1.178)-\log (1)]$ or 15.1\%. Next, as of March, Eurodollar futures were trading as if the 3-month T-bill will increase 2.25 percentage points by February of 2006. Should the 3-month T-bill rate stay at that level for the remainder of 2006, the cumulative impact of the change in interest rates on land prices will be $-0.19 *[\log (3.25)-\log ((1)]=-0.224$, or $-22.4 \%$. Finally, as of 2003:Q3, the model error is $-2.0 \%$. Should this error be halved by the end of 2006, the cumulative total forecasted percentage change to land prices over the next three years would be $15.1 \%-22.4 \%+1.0 \%=-6.3 \%$. 
This forecast for land prices can be mapped to a forecast to home prices if we assume that nominal structures prices continue to increase at $3.3 \%$ per year $(10.2 \%$ cumulatively over three years), the average rate of growth of this series for the past 5 years. Then, holding land's share of market value fixed at $0.46^{20}$ and assuming a cumulative decline in land prices of $6.3 \%$, cumulative nominal growth in home prices over the next three years would be forecasted to be approximately $10.2 \% * 0.54-6.3 \% * 0.46=2.6 \%$. This would be the smallest three-year nominal increase for home prices on record.

\section{Conclusion}

In this paper, we have documented a new method for using publicly available data to uncover a price index for constant-quality residential land prices in the United States, the first such index of its kind. With this new index and a corresponding estimate of the real stock of residential land under 1-4 unit residential structures, we have shown that the price of residential land grows more quickly but is more volatile than the price of existing homes; the price of residential land has very different time-series properties than farm land; on average, the nominal stock of land under 1-4 unit structures is equal to $50 \%$ of annual GDP; the real stock of residential land under 1-4 unit structures is growing at an average annual rate of $0.6 \%$ per year; and, at business cycle frequencies, inflation-adjusted land prices lag real residential investment by three quarters. For 2003:Q3, we estimate that the nominal value of the entire stock of residential land is approximately the same as nominal annual GDP. Finally, we show that the logarithms of the price index for land, nominal disposable personal income,

\footnotetext{
${ }^{20} \mathrm{~A}$ more exact forecast would allow land's share to change over time in a manner that is consistent with the structures and land price forecasts as well as forecasts for nominal net new investment in structures and land.
} 
and the nominal 3-month Treasury Bill rate appear to be cointegrated. A simple forecast produced using market-based assumptions about the future path of disposable income and interest rates suggests that land prices may cumulatively decline $6.3 \%$ over the next three years, implying little cumulative growth in existing home prices over this same time period. 


\section{A Data Sources and Methods}

In this first part of the Appendix, we document our procedures to revise published data and construct quarterly estimates of the replacement cost of structures, market value of land, and market value of homes. In the subsection relating to data revisions, we discuss (1) why we smooth the published CMHPI and (2) how we use the annual data in the Detailed Residential Fixed Asset Tables and annual NIPA data to construct an annual stock of commissions (which we then purge from the published replacement cost of structures). In the other subsection, we discuss how we create our quarterly time series. This involves (1) using the annual data in the Detailed Residential Fixed Asset Tables, our estimate of the annual stock of commissions, and quarterly data in the NIPA to construct the quarterly replacement cost of 1-4 unit structures, a price index for these structures, and nominal net investment in structures; (2) constructing an estimate of nominal net investment in residential land; and, (3) using data from the 2000 Decennial Census of Housing to benchmark the perpetual inventory system for the market value of homes.

\section{A.1 Revisions to Published Data}

\section{A.1.1 Altering the CMHPI}

Freddie Mac publishes a repeat sales index for existing homes in the aggregate United States called the CMHPI, "Conventional Mortgage Home-Price Index," available since 1970:Q1. Oddly, the quarterly growth rates of the published CMHPI are negatively autocorrelated (especially during the early 1970s), as shown by the solid line in the top panel of Figure 9. We

think this negative autocorrelation is not related to any fundamental property of existing home prices but rather may arise from the econometric procedures used to construct the 
CMHPI. ${ }^{21}$ As a result, we smooth the growth rates of the CMHPI using a three-quarter centered moving average (dashed line, top panel). This smoothing reduces the quarter-toquarter volatility of our price index for residential land but does not appear to have any other effect: The repeat-sales price index constructed using the smoothed growth rates is almost indistinguishable from the published CMHPI, shown in the bottom panel of Figure 9.

\section{A.1.2 Constructing an Annual Stock of Commissions}

In NIPA tables 5.4.4 and 5.4.5, annual nominal expenditures on "Brokers' commissions on the sale of structures" (5.4.5) and a price index for these expenditures (5.4.4) are reported from 1929 to 2002. We divide nominal expenditures on commissions by its published price index to uncover real annual expenditure on commissions. We then construct a real stock of commissions for year $y$, denoted $s_{y}^{c}$, via the following perpetual inventory equation

$$
s_{y}^{c}=\left(1-\delta_{y}^{c}\right) s_{y-1}^{c}+i_{y}^{c}
$$

where $\delta_{y}^{c}$ is our estimate of the depreciation rate for the stock of commissions in year $y$ that is consistent with BEA calculations (to be explained later) and $i_{y}^{c}$ is real expenditures on commissions in year $y$.

As a not-unrelated tangent, we should note that in its Detailed Residential Fixed Asset Tables, the BEA subdivides the total stock of 1-4 unit structures into 3 different categories: "new", "additions and alterations," and "major replacements." The BEA separately reports real and nominal depreciation, real gross investment, and end-of-year real and nominal replacement cost data for these three categories from 1925 through 2001. The top panel of

\footnotetext{
${ }^{21}$ The methods for producing the CMHPI are documented in Stephens et. al. (1995).
} 
Figure 10 shows that real gross investment in the "new" stock, according to the reported annual real investment data from the Detailed Residential Fixed Asset Tables, is almost exactly equal to the sum of real gross investment in permanent-site single-family structures and broker's commissions (both published in the NIPA), ${ }^{22}$ implying that commissions expenditures are included only in the "new" stock. ${ }^{23}$

We calculate the time-varying annual depreciation rate on the new stock for year $y, \delta_{y}^{n}$, as published real depreciation in the new stock for year $y$ divided by the geometric mean of the published end-of-year estimate of the new stock for years $y-1$ and $y \cdot{ }^{24}$ The bottom panel of Figure 10 plots our time-series estimate of this depreciation rate. Given commissions are lumped together with gross investment in permanent-site single-family structures in the BEA's perpetual inventory calculations for the new stock, we set $\delta_{y}^{c}=\delta_{y}^{n}$. To benchmark the perpetual inventory equation, we assume that the real stock of commissions in 1929 is equal to BEA's estimate of the real new stock of 1-4 unit structures in 1929 multiplied by the average ratio, calculated from 1950 through 2001, of real annual gross expenditures on commissions to real annual gross investment in the new stock. ${ }^{25}$ Finally, we compute the

\footnotetext{
${ }^{22}$ The real gross-investment data for permanent-site single-family investment are first available in 1958, explaining the range of data graphed in the top panel.

${ }^{23}$ This has been confirmed by conversations with BEA employees. These employees have also told us that $95 \%$ of all spending on commissions is attributable to the new 1-4 stock (the rest goes to the $5+$ stock). We make the same assumption in our calculations but do not include the 0.95 in equation 9 and subsequent relevant equations to reduce clutter.

${ }^{24}$ We use the geometric mean to more closely align depreciation, a flow throughout the year, with the end-of-year stock estimates.

${ }^{25}$ We do not include the 1929-1949 data when calculating the average ratio because the ratio has sharp spikes in this time period that are not a feature of the post-1950 data.
} 
nominal stock of commissions in year $y$ by multiplying our estimate of the real stock by an end-of-year estimate of the price index for expenditures on commissions: To compute this end-of-year estimate, we take the geometric mean of the middle-of-year estimate of the price index for years $y$ and $y+1$ as published in table 5.4.4 of the NIPA.

\section{A.2 Constructing Quarterly Time Series}

\section{A.2.1 Estimating the Quarterly Replacement Cost of Structures}

As mentioned, the BEA subdivides the total stock of 1-4 unit structures into the categories new, additions and alterations, and major replacements. We define the total stock as the sum of these three pieces after removing the stock of commissions from the new stock.

We estimate annual depreciation for the total stock as the sum of published real depreciation for the additions and alterations and major replacements stock and our estimate of real depreciation for the new stock exclusive of commissions. ${ }^{26}$ We calculate the annual time-varying real rate of depreciation for the total stock for year $y$, denoted $\delta_{y}$, as real depreciation for year $y$ divided by the geometric mean of the real total stock for years $y$ and $y-1$. Then, we set the quarterly depreciation rate for quarter $q$ of year $y$ equal as $\left(1-\delta_{y, q}\right)=\left(1-\delta_{y}\right)^{\frac{1}{4}}$ up to 2001:Q4. For 2002:Q1 forward, we set $\delta_{y, q}$ equal to its average value from 1996:Q1-2001:Q4, 1.48\% at an annual rate.

If we had quarterly data on real gross investment in the total 1-4 stock (which we will denote $i_{y, q}$ ) for quarter $q$ of year $y$, we would calculate the quarterly total stock in quarter $q$ of year $y$ by the perpetual inventory equation:

$$
s_{y, q}=s_{y, q-1}\left(1-\delta_{y, q}\right)+i_{y, q}
$$

\footnotetext{
${ }^{26}$ This is published real depreciation for the new stock minus our estimate of depreciation for the stock of commissions.
} 
However, we do not observe $i_{y, q}$ at the quarterly frequency. We only observe $i_{y, q}^{n}+i_{y, q}^{a *}$ where $i_{y, q}^{n}$ is real gross investment in new single-family (1-4 unit) permanent-site structures excluding commissions and $i_{y, q}^{a *}$ is real gross investment in additions and alterations and major replacements for the entire stock of structures including $5+$ units.

We define the variable $x_{y}$ as the difference between real annual gross investment in year $y$ for our total stock, available as the sum of real investment in the new, additions and alterations, and major replacements stock from the Detailed Residential Fixed Asset Tables minus real annual expenditures on commissions, and the annual sum of what we observe from NIPA, i.e.

$$
x_{y}=\sum_{q=1}^{4}\left(i_{y, q}^{n}+i_{y, q}^{a *}\right)-i_{y} .
$$

Typically $x_{y}$ is quite small and on average (1970-2001), $x_{y}$ is $2 \%$ of $i_{y}$. To generate a quarterly series for real gross investments in the total stock, we allocate $x_{y}$ evenly across all four quarters of the year and then calculate the total real stock of 1-4 structures using the perpetual inventory method,

$$
s_{y, q}=s_{y, q-1}\left(1-\delta_{y, q-1}\right)+i_{y, q}^{n}+i_{y, q}^{a *}-x_{y} / 4
$$

To implement (12) for 2002:Q1 and after, we hold $x_{y} / 4$ as a fraction of the sum of $i_{y, q}^{n}+i_{y, q}^{a *}$ fixed at its average value from 1996:Q1 - 2001:Q4, 1.7\%.

We calculate the quarterly price index for the revised total stock of 1-4 unit structures, $p_{y, q}^{s}$, by scaling the quarter-to-quarter movements in the published NIPA price index for new single-family structures $\left(p_{y, q}^{s, n}\right)$ such that the total re-scaled growth throughout the year matches the growth in the annual price index for the revised total stock. The annual price index for the total stock can be calculated as the ratio of the annual nominal total stock to the annual real total stock. From 1970:Q1 to 2001:Q4, we find that $p_{y, q}^{s, n}$ cumulatively grows about $3 \%$ more than $p_{y, q}^{s}$. The differences over a two-year period are typically small, and for 
the post-2001 data, we assume the growth rates are identical.

Finally, given our estimate of the quarterly real total stock and its price index, we define quarterly net nominal investment in the revised total stock of 1-4 unit structures in quarter $q$ of year $y$ as $p_{y, q}^{s} \Delta s_{y, q}$, where $\Delta s_{y, q}$ is the first difference of our quarterly real total stock. Note that in equation (7) and the other equations in the Accounting and Measurement sections of this paper, $p_{y, q}^{s} \Delta s_{y, q}$ is written simply as $p_{t}^{s} \Delta s_{t} .{ }^{27}$

\section{A.2.2 Estimating Quarterly Net Investment in New Land}

The Census collects data on the sales price of homes built-for-sale and the value of construction contracts for owner-built homes and it uses this data to infer the value put in place for residential construction. In the case of homes built for sale, estimates of the value of landscaping, appliances, realtor/broker fees, marketing/finance costs, and raw land are subtracted from the sales price by the Census to determine the construction value put in place. ${ }^{28}$ The Census assumes the share of the home's sale price going to each of these factors is fixed over time when calculating value put in place; in the case of land, raw land is assumed to account for $10.8 \%$ of the sales price of a home built for sale. ${ }^{29}$ Since 1996, after all the subtractions, Census sets value put in place to $84.2 \%$ of the sales price of a home for homes built for sale; for owner-built homes, it is $110.2 \% .^{30}$ For data prior to 1982 , the value put in place factor is set to $78.13 \%$ for homes built for sale, which is based on a similar study

\footnotetext{
${ }^{27}$ Remember that in these earlier sections of the paper we do not need to draw a distinction between yearly and quarterly data.

${ }^{28}$ For owner-built homes, only landscaping and appliances are subtracted.

${ }^{29}$ The shares are based on an unpublished 1999 Census study summarized in a memorandum from Dennis Duke to Paul Hsen entitled, "Summary of the One-family Construction Cost Study" dated August 1, 2000.

${ }^{30}$ The additional $10 \%$ reflects expected revisions to the contract to incorporate additional work.
} 
conducted in 1982. For data between 1982 and 1996, the value-put-in-place factor is set to gradually increase from $78 \%$ to $84 \%$.

We use all of this information to infer a nominal net new-land series that is consistent with Census's estimates of value put in place: We assume that the value of net new contributions to the stock of residential land in quarter $q$ of year $y$, denoted $p_{y, q}^{l} \Delta l_{y, q}$, equals a time-varying scale factor $\sigma_{y, q}$ times nominal gross investment in permanent-site single-family (1-4 unit) structures. We include all single-family homes in these calculations, including owner-built homes, because the vacant land underneath a new owner-built home should not have been included in the value of residential land prior to the building of the new structure. With this specification, we ignore teardowns and effectively assume that all new houses are built on new land. Importantly, this also implies that we assume that residential land under 1-4 unit structures is never converted to other uses. For 1996 and later dates, the scale factor $\sigma_{y, q}$ we apply is $0.108 / 0.842=0.1284$; for 1982 and earlier years, we apply a scale factor of 0.1384 (reflecting the different value-put-in-place factor of 0.7813 ); and, we decrease the scale factor gradually from 1982 to 1996, reflecting the increase in the value put in place factor from $78 \%$ to $84 \%$.

We calculate the value of new land as

$$
p_{y, q}^{l} \Delta l_{y, q}=\sigma_{y, q}\left(p_{y, q}^{s, n} i_{y, q}^{n}\right)
$$

where $p_{y, q}^{s, n} i_{y, q}^{n}$ denotes NIPA data on nominal gross expenditures on (1-4 unit) permanent-site single-family structures. Figure 11 plots our estimates of the nominal value of new land. The rather large peak-to-trough movements in the early part of the series are not an artifact of any of our measurement procedures; these movements reflect movements in the NIPA valueput-in-place series for the 1-4 stock of structures. As shown in the panel, for 2003:Q3 our estimate of the nominal value of new land being added to the stock is $\$ 37.2$ billion (annual rate). For comparison, the total nominal stock of land in 2003:Q3 is $\$ 7,845$ billion. 


\section{A.2.3 Benchmarking the Market Value of Homes}

So far, we have discussed our computation of all of the key ingredients to the perpetual inventory accounting of the nominal market value of homes, equation (7). In this section, we discuss exactly how we benchmark the market value.

Data from the 2000 Decennial Census of Housing (a one percent sample of all housing units in the United States), available at the IPUMS web site http://www.ipums.umn.edu/usa/index.html, contains information for each housing unit on ownership status of the dwelling, number of units in the structure, and the house value. The ownership status is reported as either "owned," "rented," or "N/A" which we interpret as a vacant unit or a vacation home. The number of units in the structure is also reported, the categories of which are listed in the rows of Table 3. Finally, house values are also recorded for many units, with the maximum reported value fixed at $\$ 1$ million. ${ }^{31}$ In Table 3 , we show the estimated distribution of housing units in 2000 based on this data by number of units in the structure; in this and subsequent tables, each survey response is always weighted by its reported sample weight in order to produce estimates of the aggregate distribution. This table shows that of the 116 million housing units in the United States, about $73 \%$ are located in a 1-4 unit structure.

Tables 4 and 5 document uncertainty about the total market value of homes that arises from use of the IPUMS Census data. The uncertainty stems from the fact that the value of the home is not always reported. For owner-occupiers, the house value is always reported; for renters it is never reported; and for vacant units, it is sometimes reported. Further,

\footnotetext{
${ }^{31}$ The exact Census question is, "What is the value of this property; that is, how much do you think this house and lot, apartment, or mobile home and lot would sell for if it were for sale?" The potential responses are grouped into bins, for example: Less than 10,000; 10,000 to 14,999; 15,000 to 19,999; etc. Except for the top-code of $\$ 1$ million, the value is specified as the midpoint of the bin.
} 
homes with a value of greater than $\$ 1$ million are always reported to have a value of exactly $\$ 1$ million, the top-code. Note that we are ignoring two other sources of error. First, we assume that when a structure type is reported as "N/A," it is not a home from a 1-4 unit building. Tables 4 and 5 show the market value of structures of reported type N/A is about $\$ 500$ billion; if we were to instead proportionately allocate this market value to the 1-4 unit total, the 1-4 unit total would increase by about $\$ 350$ billion. Second, we are ignoring any errors resulting from lumping the market value of a home into bins and assigning a home's value as the midpoint of the bin.

Tables 4 and 5 highlight the sensitivity of the aggregate market value to different imputations for non-reported home values. These tables show that, depending on the assumptions, the market value of homes in 1-4 unit structures ranges from $\$ 12.5$ to $\$ 14$ trillion in 2000. Table 4 shows the distribution of average house value, by type of structure, for owner-occupiers and for the vacant homes, with the top-code kept unchanged at $\$ 1$ million dollars. Although the response rates of house values for vacant homes are not impressive, there are so many people in this one-percent sample that the raw number of responses for any cell seems high enough for accurate inference. For example, there are 154 raw (unweighted) reported home values for vacant 10-19 unit structures, even though vacant homes represent only $11 \%$ of the 10-19 unit structure category (see Table 3) and only 3\% (weighted) of households in a vacant unit in this type of structure report a value. Table 4 shows that the average owner-occupied value of homes in 1-4 unit structures is about $25 \%$ greater than that of vacant homes, but for homes in larger buildings the opposite is true.

The aggregate value of the housing stock is computed under two different assumptions in Table 4. In the first, called "Method 1," all missing values for any given type of structure are set to the unconditional average reported value for that type of structure. In the second, "Method 2," the missing values for rental units and vacants are set to the average reported 
value for the vacants. Conceptually, Method 2 treats the stocks of vacant and rentals (conditional on the number of units in the building) as fundamentally different than the stock of owner-occupied units, whereas Method 1 treats the stock for any given number of units in a building as homogeneous. As the row "Subtotal: 1-4 Unit" shows, the difference in aggregate value of the 1-4 unit significantly changes with each assumption: Method 1 produces a market value that is $\$ 1$ trillion (7.5\%) higher than Method 2 .

In Table 5, we repeat the same exercise as in Table 4 but replace the top-code with $\$ 1.83$ million, our estimated average value of homes that are worth more than $\$ 1$ million in 2000 . We compute this average by taking the average value of homes worth more than $\$ 1$ million from the 2001 Survey of Consumer Finances, exactly $\$ 2$ million, and deflate this average by growth in the quarterly CMHPI (8.45\%) from the 2000:Q2 to 2001:Q3, the approximate dates of the respective surveys. ${ }^{32}$ Although the percentage of homes that has been top-coded is pretty small - approximately $1 \%$ - we find the impact of top-coding on the aggregate house values is quite substantial because these homes are so valuable relative to the average. The total impact of top-coding on the estimate of the size of the stock of homes in 1-4 unit structures is about $\$ 500$ billion. This can be seen by comparing Method 1 and 2 subtotals from Table 4 (13.5 and 12.5 trillion, respectively) with the Method 1A and 2A subtotals from Table 5 (14.0 and 12.9 trillion).

In all cases, we find that the market value of homes in 1-4 unit structures accounts for between $70 \%$ and $75 \%$ of the market value of all homes. Our preferred ("baseline") estimate of the market value of the 1-4 unit stock in 2000 is $\$ 12.94$ trillion from Method 2A. We assume this to be an estimate of the stock at the end of the second quarter of 2000 .

\footnotetext{
${ }^{32}$ We thank Kevin Moore for performing these calculations for us using confidential data from the 2001 Survey of Consumer Finances.
} 


\section{B Sensitivity Analysis}

In this section of the Appendix, we document the sensitivity of our findings to various sensible changes to our procedures and/or data. In the first section, we show specifically why we do not use the Flow of Funds market value data. The latter sections show the impact of changes to assumptions about (a) the nominal value of new land each year that is converted from other sources and (b) the market value of the stock of homes in 1-4 unit structures based on year 2000 Census data on our land price and quantity series.

\section{B.1 Flow of Funds Data}

The Flow of Funds Accounts (FoF), produced by the Federal Reserve, publishes endof-year estimates of the market value of aggregate household real estate as well as the replacement cost of the aggregate structures. ${ }^{33}$ The aggregate market value of residential real estate (including the stock of units in buildings larger than 5 units) held by households and nonfarm noncorporate businesses can be calculated as the sum of line 4 of Flow of Funds Table B.100 and line 3 of Table B.103 minus an unpublished estimate of the value of vacant land. Similarly, the replacement cost for this stock can be calculated as the sum of line 45 of Table B.100 and line 32 of Table B.103. Note that these calculations exclude the residential real estate held by nonprofit organizations (about $7 \%$ of the total) and a tiny amount of real estate held by nonfarm nonfinancial corporate businesses. ${ }^{34}$

As shown in Figure 12, the FoF data suggest that the real quality-adjusted stock of

\footnotetext{
${ }^{33}$ The Flow of Funds replacement cost data exactly matches the published data in the BEA Fixed Assets tables. For the analysis in this section, we do not purge our estimate of the stock of commissions from the replacement cost data.

${ }^{34}$ Including these pieces does not change the key result of this section.
} 
residential land more than tripled between 1980 and 1985 and has been falling since the mid1980s. The most likely explanation for this odd result is that the market value of homes in the Flow of Funds is not constructed using a perpetual inventory system like that described in equation (7). In certain key years, the owner-occupied portion of the market value of homes is benchmarked to estimates based on the American Housing Survey, produced by the United States Census Bureau; home values between the benchmark years are calculated via interpolation. The benchmark procedures do not appear to be consistent across survey years. ${ }^{35}$ Although the FoF benchmark to the 1999 AHS may be beyond reproach, it is simply not known exactly how the 1983 benchmark procedures, for example, compare with those of the 1999 benchmark. Our guess is that the 1983 and 1985 benchmark procedures are simply incomparable with earlier and later benchmarks. ${ }^{36}$

\section{B.2 New Land}

In our baseline calculations we assume, like the Census, that the nominal fraction of the value of new housing accounted for by land is roughly fixed over time, implying an elasticity of substitution between land and other factors in the production of new housing equal to 1.0. Using micro-data on lot sales and home sales in the Portland, Oregon region, Thorsnes (1997) concludes that the hypothesis of an elasticity of substitution of 1.0 can not be rejected. However, many housing researchers have estimated an elasticity of substitution significantly less than 1.0; see McDonald (1981) for an older review.

To test the sensitivity of our results to the assumption of an elasticity of substitution of

\footnotetext{
${ }^{35}$ For example, one of the benchmark procedures assigns a value to an expensive home whose value has been "top coded" in the American Housing Survey data. The top-coded values change across surveys.

${ }^{36} \mathrm{As}$ a consequence of this and other research, the FoF measure of housing wealth is currently under review.
} 
1.0, we repeat our analysis assuming that real new land and real new structures are combined in fixed proportions to build real new housing units according to a Leontief production function; that is, in our alternative specification, $\Delta l_{y, q}=\kappa i_{y, q}^{n}$, where $\kappa$ is a constant. Since the land-structures mix in real units of new housing is independent of price, in this alternative specification the elasticity of substitution is 0.0 .

Noting that our baseline specification of the "scale factor" $\sigma_{y, q}$ satisfies the relationship $p_{y, q}^{l} \Delta l_{y, q}=\sigma_{y, q}\left(p_{y, q}^{s, n} i_{y, q}^{n}\right)$ for all quarters $q$ and years $y$, we use the estimate of $\sigma_{y, q}=0.1284$ from the 1999 Census study to identify an initial estimate of $\kappa$. That is, given our estimate of the time-series path of land prices $p_{y, q}^{l}$ from our baseline procedures, we set $\kappa$ as

$$
\kappa=\frac{\Delta l_{y, q}}{i_{y, q}^{n}}=0.1284\left(\frac{p_{1999,2}^{s, n}}{p_{1999,2}^{l}}\right)=0.1215 .
$$

Given this estimate for $\kappa$ we construct a new estimate of nominal net new investments in land as $p_{y, q}^{l}\left(\kappa i_{y, q}^{n}\right)$ and then construct a new time-series path for the market value of the housing stock according to equation (7). After this, we compute the implied revised price index for residential land prices according to (8); if the revisions are significant, we update our guess of $\kappa$ based on equation (14) and repeat the process as just described until the revisions to the time-series path of land prices are negligible.

Figure 13 shows the impact of this alternative specification to land prices and quantities. The top-left panel of Figure 13 plots the baseline and alternative scale factor linking nominal net new investment in structures to nominal net new investment in residential land. The scale factor from the alternative specification is simply $\kappa\left(p_{y, q}^{l} / p_{y, q}^{s, n}\right)$ : The logic of the alternative scale factor is that while real proportions between land and structures remain fixed, nominal proportions vary with relative prices. Is this a reasonable assumption for the scale factor? We don't have much evidence on the subject, but Carliner (2003) suggests that the share of raw land as a fraction of home prices based on a survey of big builders has decreased from 
$1995(10.7 \%)$ to 2001 (7.2\%), contrary to the pattern displayed in Figure 13. ${ }^{37}$

Regardless, this alternative specification has almost no impact on our results. The price index relative to consumption prices (top-right panel) and nominal-quantity of land (bottomleft panel) are basically unchanged. The real quantity of land changes very slightly (bottomleft panel) and correspondingly, the growth rate of the real stock of declines (bottom-right panel). But overall, the graphs in Figure 13 suggest that reasonable changes to our assumption about the elasticity of substitution between land and structures in new homes likely will not meaningfully alter our quality-adjusted land-price or quantity series.

\section{B.3 Market Value of Homes}

In Figure 14, we show the impact on land prices and quantities if we assume that the aggregate value of the stock of housing in the second quarter of 2000 is $\$ 13.97$ trillion, as in Method 1A of Table 5, rather than $\$ 12.94$ trillion from Method 2A, the baseline estimate. The top-left panel shows the impact of this alternative assumption on the full time-series paths of the nominal market value of the housing stock and land. Obviously, by increasing the market value of homes in 2000, the market value of land in 2000 must increase since the replacement cost of structures has not changed. ${ }^{38}$

\footnotetext{
${ }^{37}$ The exact four percentages reported in Table 3 of Carliner (2003) are $10.7 \%$ for $1995,7.6 \%$ for 1999 , $7.0 \%$ for 2000 , and $7.2 \%$ for 2001 .

${ }^{38}$ It is less obvious why the alternative market value of the housing stock should be relatively higher than the baseline in $1970(13.5 \%)$ than in $2000(7.5 \%)$. This result arises because we have not changed our time series estimates of the net new additions to land and structures entering into equation (7). Since these two time-series are fixed between the alternative and baseline scenarios, and given the time series of growth rates to home prices is unchanged, by construction the market value of homes must be relatively higher in earlier periods in the alternative scenario.
} 
The remaining three panels of this chart show the impact of this alternative specification on land prices and quantities. Clearly, any increase in the market value of homes is matched one-for-one by an increase to the market value of land, implying an increase in land's share of market value relative to baseline. The top-right and bottom-left panels indicate that this alternative specification, however, has little impact on both our estimates of the growth rate of land prices relative to consumption prices and the growth rate of the nominal stock of land. Finally, although the level of the real stock of land is higher in this alternative scenario (not shown), the growth rate of the real stock of land declines relative to the baseline, shown in the bottom-right panel. This occurs because the nominal stock of land has increased relative to baseline but our estimates of nominal net new investment in the stock of residential land have not changed. 


\section{REFERENCES}

Carliner, M., 2003, "New Home Cost Components", Housing Economics (March), 7-11.

Cooley, T. and E. Prescott, 1995, "Economic Growth and Business Cycles", in Thomas Cooley (ed.) Frontiers of Business Cycle Research, Princeton: Princeton University Press.

Davis, M. and J. Heathcote, 2004, "Housing and the Business Cycle”, Federal Reserve Board Finance and Economics Discussion Series Working Paper no. 2004-11.

Duke, D., 2000, "Summary of the One-family Construction Cost Study", unpublished memorandum to Paul Hsen, United States Census Bureau.

Goldsmith, R. and R. Lipsey, 1963, "Studies in the National Balance Sheet of the United States, Volume I", Princeton: Princeton University Press.

Hamilton, J., 1994, “Time Series Analysis”, Princeton: Princeton University Press.

McDonald, J., 1981, "Capital-land Substitution in Urban Housing: A Survey of Empirical Estimates”, Journal of Urban Economics 9 (1), 190-211.

Poterba, J., 1984, “Tax Subsidies to Owner-occupied Housing: An Asset Market Approach", Quarterly Journal of Economics 99, 729-752.

Poterba, J., 1991, "House Price Dynamics: The Role of Tax Policy and Demography", Brookings Papers on Economic Activity (2), 143-203.

Stephens, W., Li, Y., Lekkas, V., Abraham, J., Calhoun, C. and T. Kimner, 1995, "Conventional Mortgage Home Price Index", Journal of Housing Research 6 (3), $389-418$.

Thorsnes, P., 1997, “Consistent Estimates of the Elasticity of Substitution between Land and Non-Land Inputs in the Production of Housing", Journal of Urban Economics 42 (1), 98-108.

Topel, R. and S. Rosen, 1988, "Housing Investment in the United States", Journal of Political Economy 98 (4), 718-740.

U.S. Department of Commerce, Bureau of Economic Analysis, 2003, "Fixed Assets and Consumer Durable Goods in the United States, 1925-97”, Washington, DC: U.S. Government Printing Office. 


\section{FIGURE 1 \\ 5-YeAr Growth AFTER AdJUSTING FOR INFLATION ${ }^{1}$ \\ FOR HOME-PRICE INDEXES OF SELECTED MSAS \\ 1980:Q1 - 2003:Q3 (QUARTERLY)}
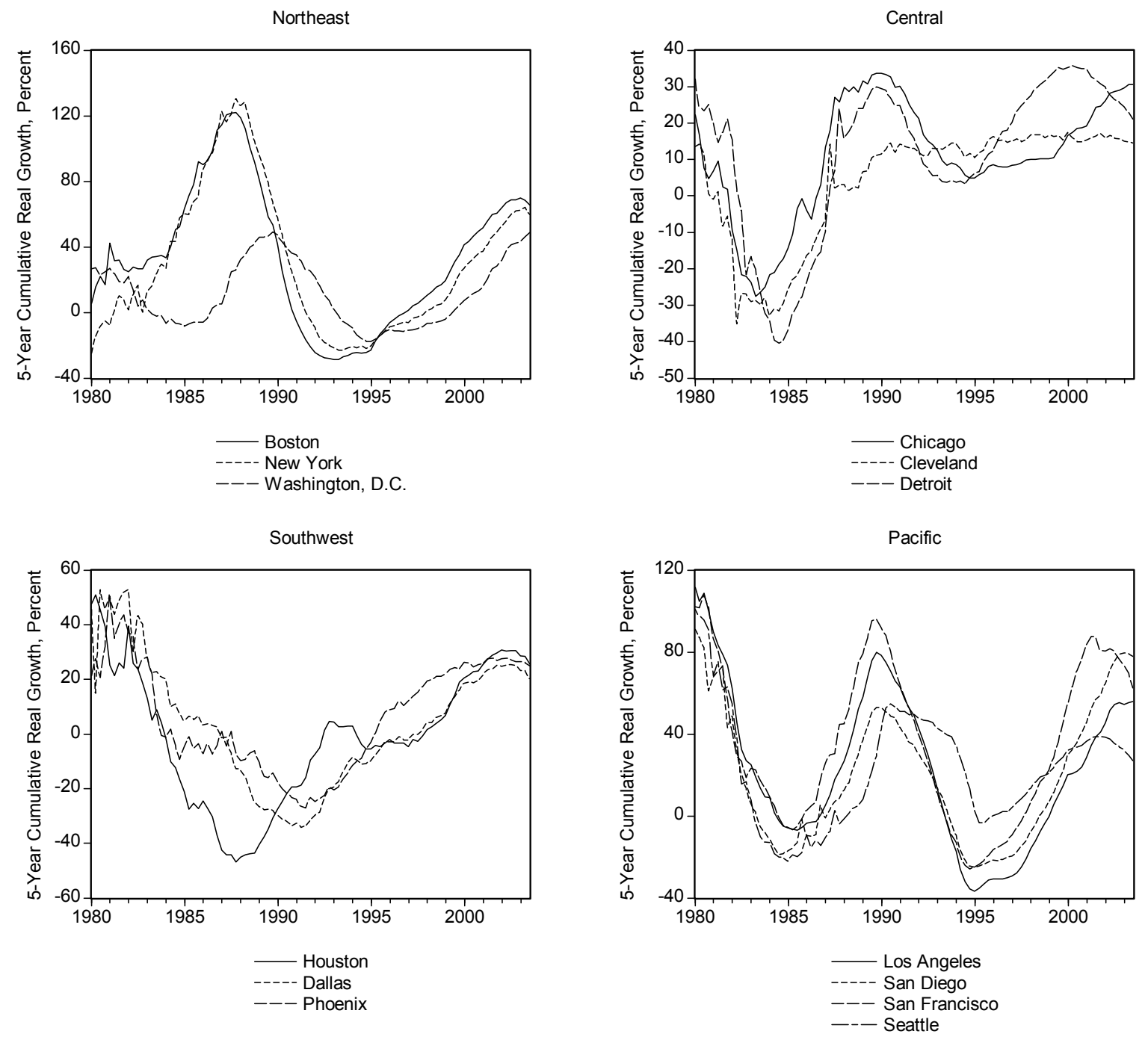

\footnotetext{
${ }^{1}$ Values refer to the cumulative 5-year growth, ending in the listed period, in the reported price index of the MSA (from Freddie Mac CMHPI) minus the cumulative 5-year growth in the consumption price index excluding food and energy as reported in the National Income and Product Accounts (NIPAs). For example, the 2003:Q3 Boston number (65.7 percent) is the 5-year cumulative growth in the CMHPI for the Boston MSA ending in 2003:Q3 (74.1 percent) minus the 5-year cumulative growth in core-consumer prices ending in 2003:Q3 (8.4 percent).
} 
FIGURE 2

RATIO OF NOMINAL STOCK OF COMMISSIONS

To Total Nominal RePorted REPlacement Cost OF 1-4 Unit StRUCTURES $1929-2001$ (ANNUAL) ${ }^{2}$

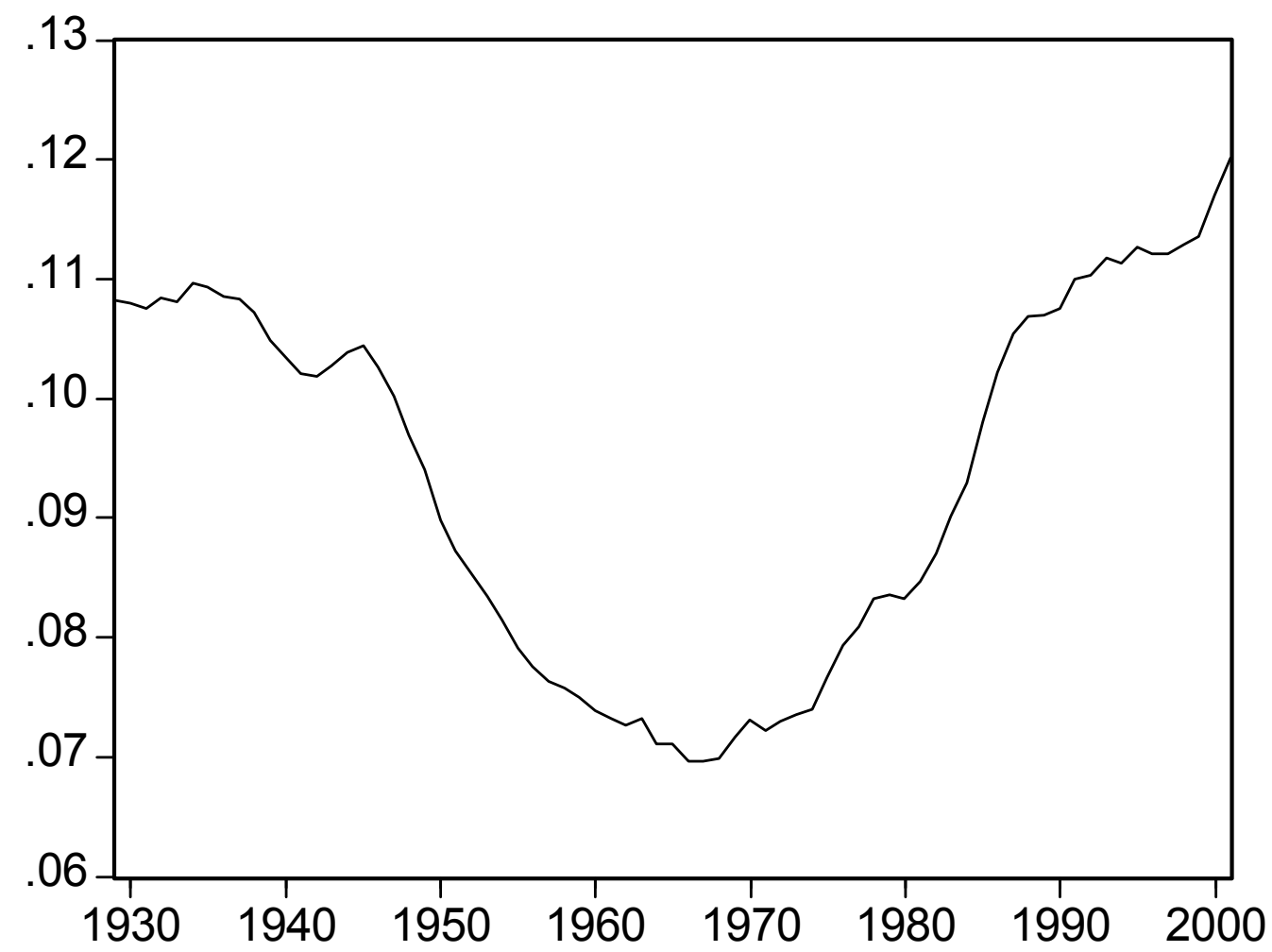

2 See Appendix A for details on construction of the data. 
FIGURE 3

PRICE OF RESIDENTIAL LAND 3

1970:1 - 2003:3 (QUARTERLY)
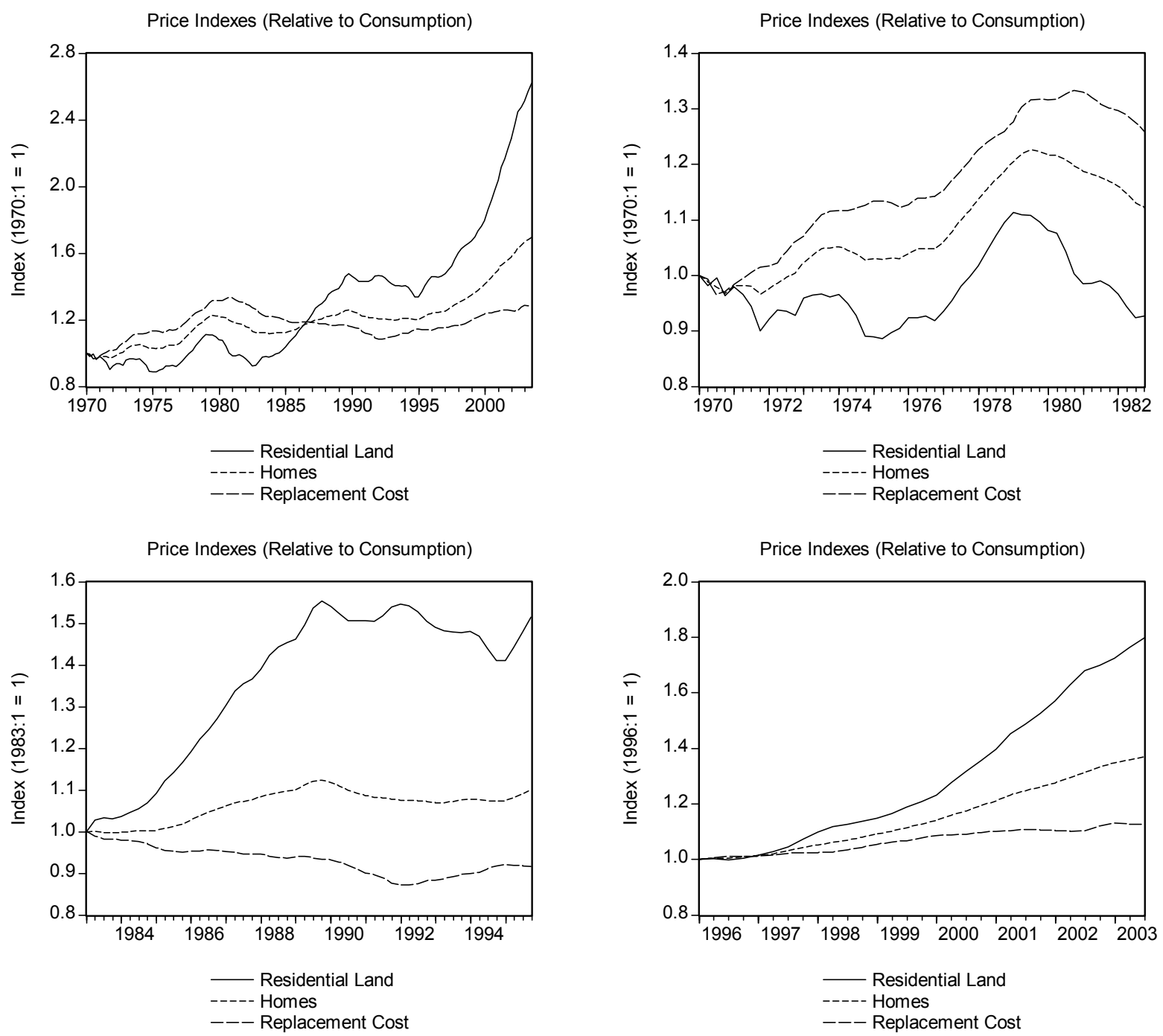

3 The price indexes in these graphs are expressed relative to the NIPA consumption price index excluding food and energy. 
FIGURE 4

LAND's SHare of THE AgGRegate Market Value of Homes 1970:1 - 2003:3 (QUARTERLY)
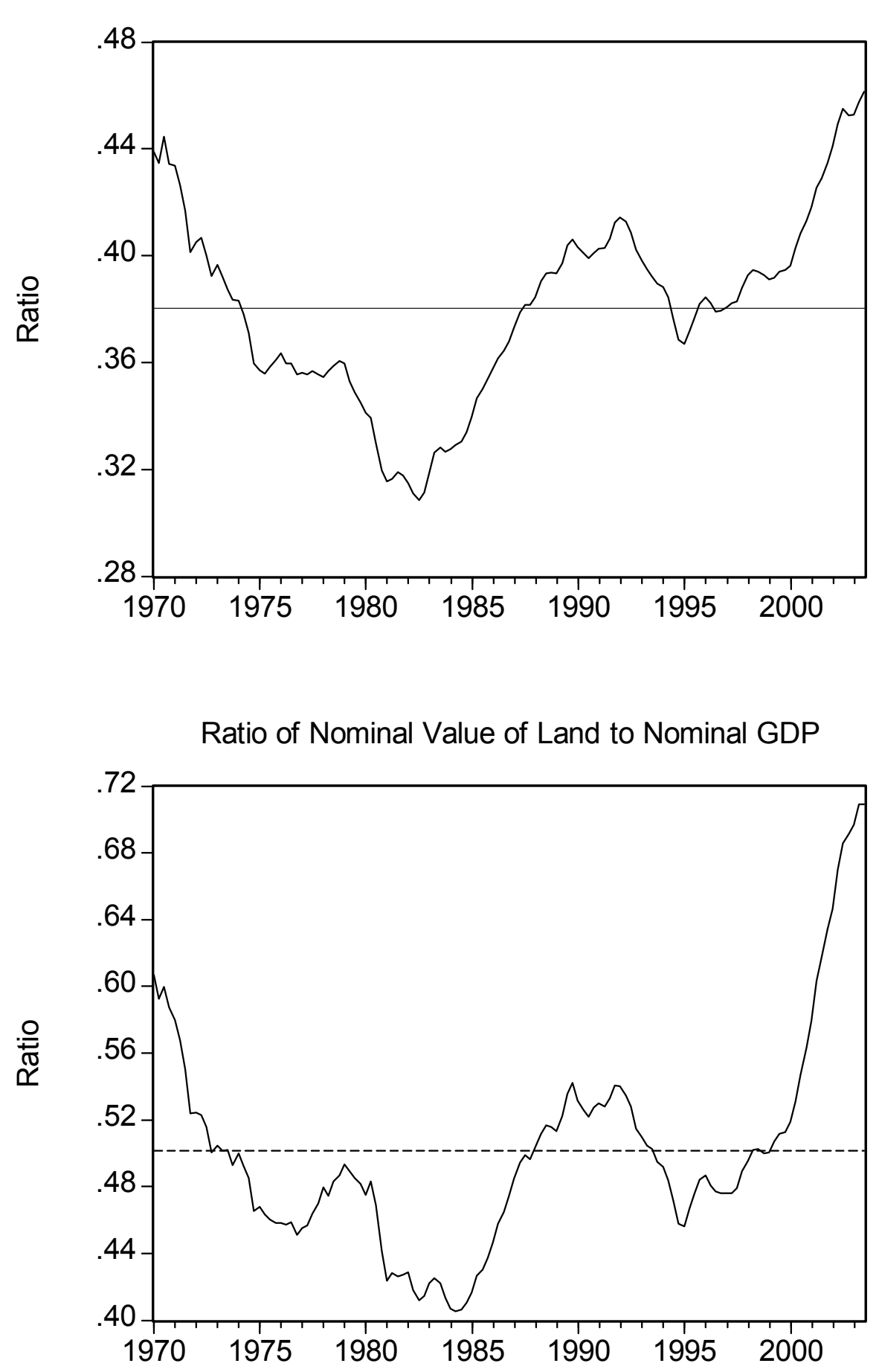


\section{FIGURE 5}

PRICE OF RESIDENTIAL LAND AND FARM LAND ${ }^{4}$

1970:1 - 2003:3 (QUARTERLY)
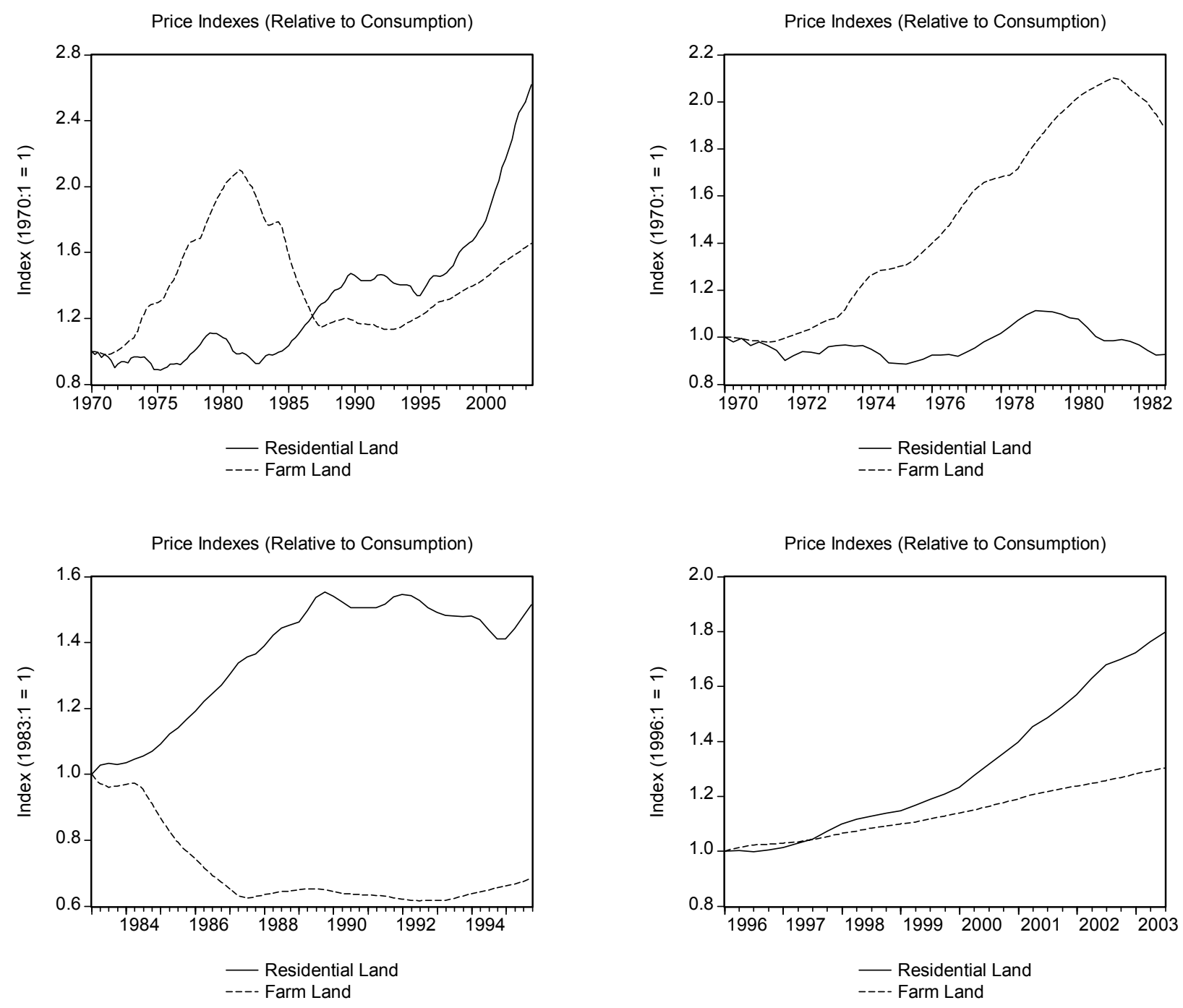

4 The price indexes in these graphs are expressed relative to the NIPA consumption price index excluding food and energy. 
FIGURE 6

STOCK OF RESIDENTIAL LAND 1970:1 - 2003:3 (QUARTERLY)

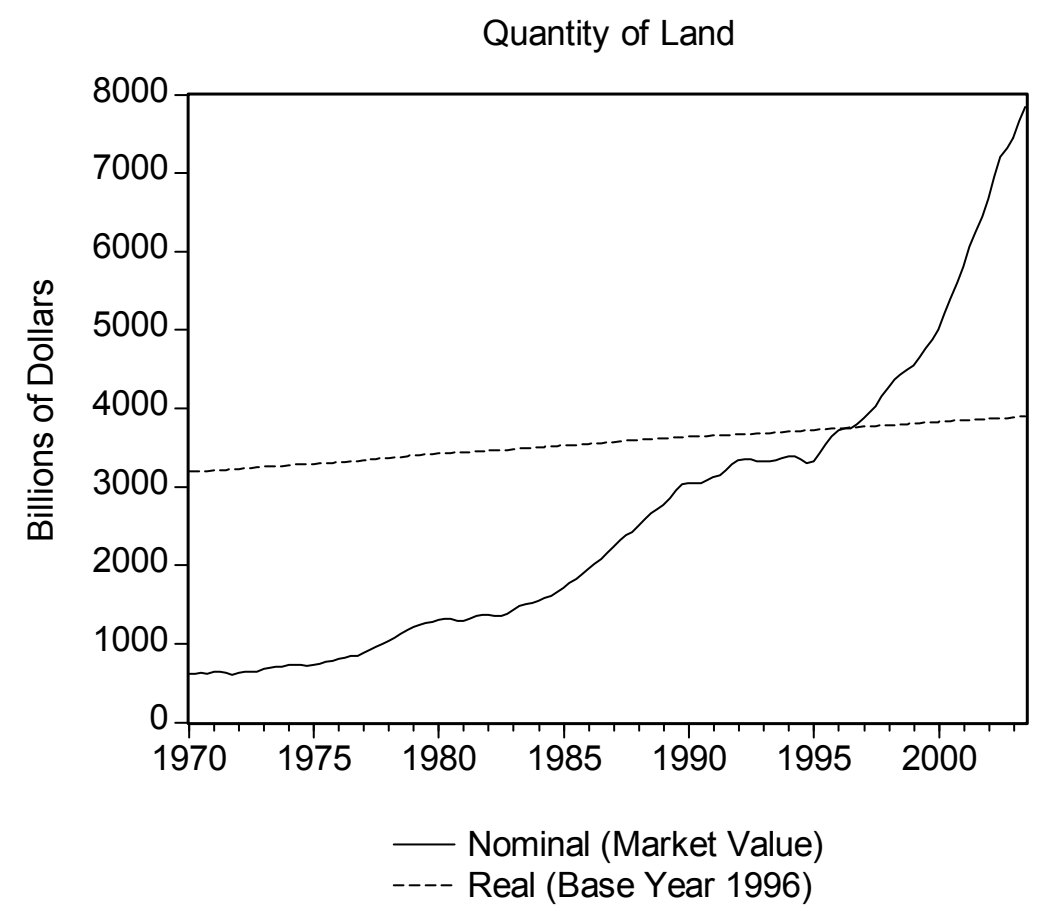

Annualized Growth Rate, Real Stock of Residential Land

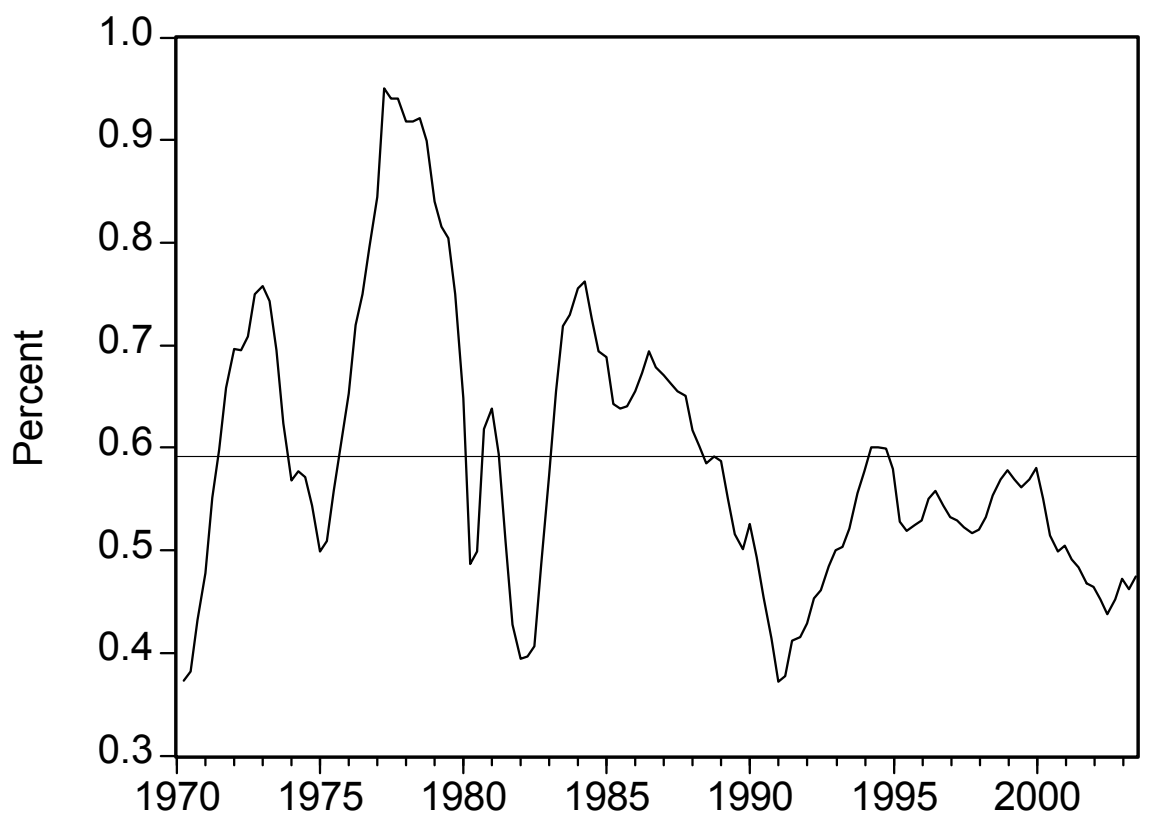


TABLE 1

Business-Cycle Properties of a Few LAND-Related SERIES

ESTIMATED 1970:1 - 2003:3 USING QUARTERLY DATA ${ }^{5}$

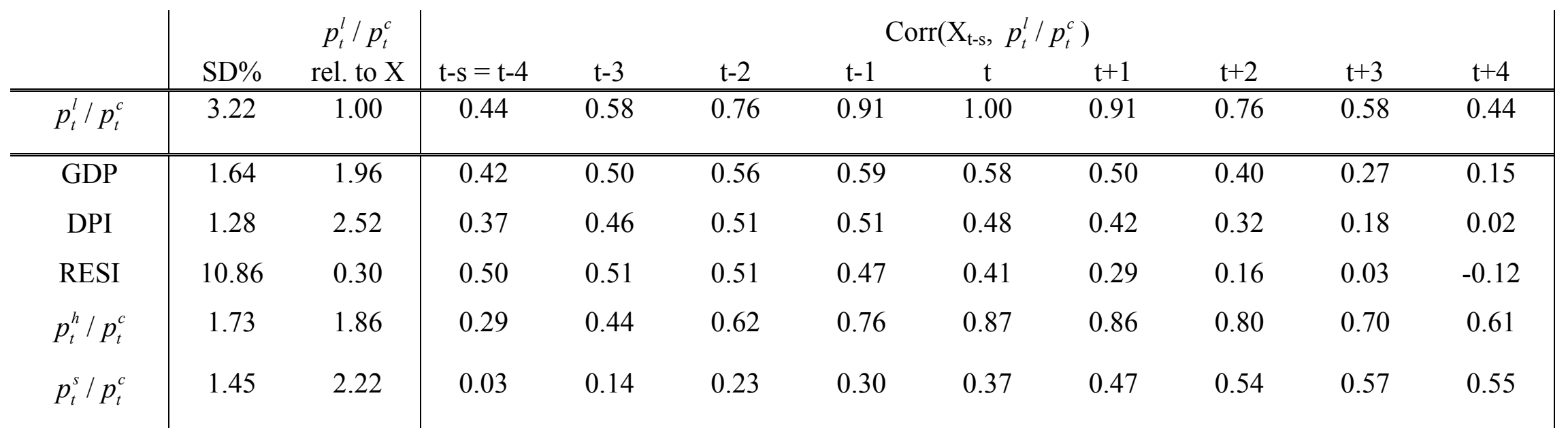

${ }^{5} p_{t}^{l} / p_{t}^{c}=$ the price index for constant-quality residential land divided by the NIPA consumption price index excluding food and energy; GDP = real chainweighted GDP (\$1996); DPI = real disposable personal income $(\$ 1996) ; \mathrm{RESI}=$ real chain-weighted residential investment in structures $(\$ 1996) ; p_{t}^{h} / p_{t}^{c}=$ modified Freddie Mac CMHPI divided by the NIPA consumption price index excluding food and energy; and $p_{t}^{s} / p_{t}^{c}=$ the price index for the replacement cost of 1-4 unit structures divided by the NIPA consumption price index excluding food and energy. All variables are measured quarterly; the price variables are measured at the end of the quarter; the NIPA consumption price index excluding food and energy is converted from an average throughout the quarter (as published) to an end-of-quarter basis by taking the geometric mean of the reported price index for the current and future quarter. All data are available for public download at http://morris.marginalq.com. GDP, DPI, and RESI are taken directly from the NIPA; the CMHPI has been smoothed to remove negatively autocorrelated growth-rate spikes; and the price index for the replacement cost of structures is taken from the NIPA and adjusted (see paper for details). All variables have been logged and HP-filtered with parameter $\lambda=1600$. 
FIGURE 7

5-Year Cumulative Returns, Nominal AND ReAL

1970:1 - 2003:3 (QUARTERLY)

5-Year Cumulative Nominal Returns

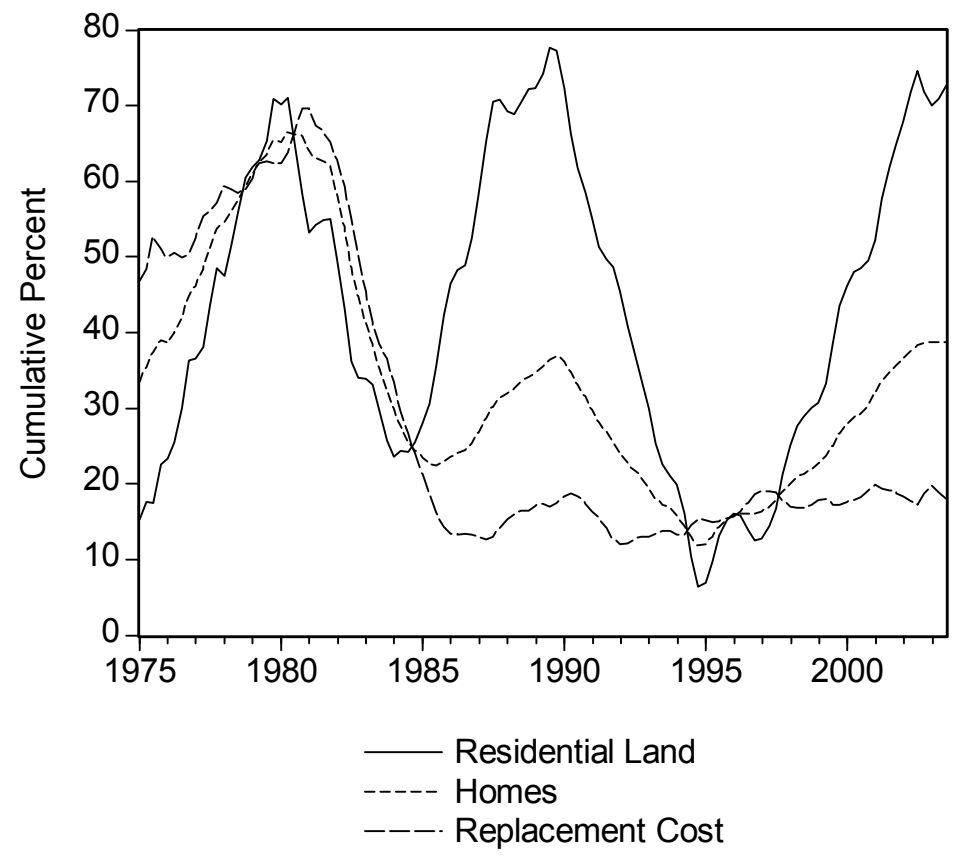

5-Year Cumulative Real Returns

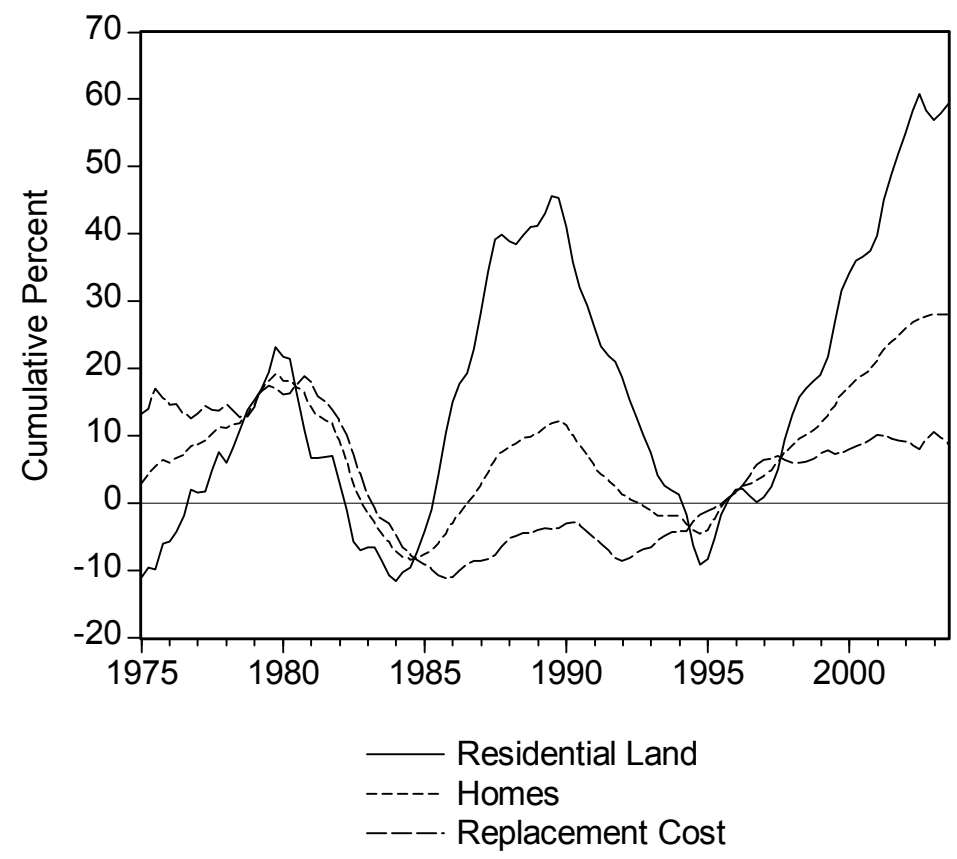


TABLE 2

REGRESSION COEFFICIENTS, DEPENDENT VARIABLE $=\log \left(p_{t}^{l}\right)$

ESTIMATED 1970:Q1 - 2003:Q3

\begin{tabular}{c|cc} 
VARIABLE $^{6}$ & COEFFICIENT $^{7}$ & ADJUSTED T-VALUE $^{8}$ \\
\hline \hline $\log \left(y_{t}\right)$ & 0.92 & 15.44 \\
\hline $\log \left(r_{t}\right)$ & -0.19 & -2.87 \\
\hline \hline
\end{tabular}

\section{UNIT RoOT TESTS, RESIDUALs ${ }^{9}$}

\begin{tabular}{|c|c|c|}
\hline \multicolumn{2}{|c|}{ EVIEWS TEST } & REJECT NULL OF UNIT ROOT? \\
\hline AGUMENTED DICKEY-FULLER & NO INTERCEPT & YES $(1 \%)$ \\
\hline & INTERCEPT & YES $(5 \%)$ \\
\hline PHILLIPS-PERRON & NO INTERCEPT & YES $(1 \%)$ \\
\hline & INTERCEPT & YES (1\%) \\
\hline
\end{tabular}

${ }^{6} p_{t}^{l}=$ the quarterly price index for residential land; $y_{t}=$ quarterly nominal disposable personal income;

$r_{t}=$ the nominal 3-month Treasury bill rate, effective annual yield. These variables are cointegrated according to a Johanssen test performed in Eviews.

${ }^{7}$ Coefficients are estimated in Eviews using the Stock-Watson procedure with two leads and lags of all variables included in the regression.

${ }^{8}$ T-values are calculated according to Hamilton (1994), p. 611.

9 The error term is calculated as $\log \left(p_{t}^{l}\right)-0.92 \log \left(y_{t}\right)+0.19 \log \left(r_{t}\right)-c_{0}$ where $\mathrm{c}_{0}$ sets the mean of the error terms to zero over the sample period. "Augmented Dickey Fuller" and "Phillips Perron" refer to the Augmented Dickey Fuller test and Phillips Perron test of a unit-root process in Eviews. "Intercept" and "No Intercept" refer to the option on whether or not to include an intercept term for each of these tests. The reported percentage is the probability of a Type I error according to each test: in each case, the test statistic is less than the critical value. 
FIGURE 8

ERRORS AND PREDICTIONS OF THE ECONOMETRIC MODEL 1970:Q1 - 2003:Q3

Model Errors

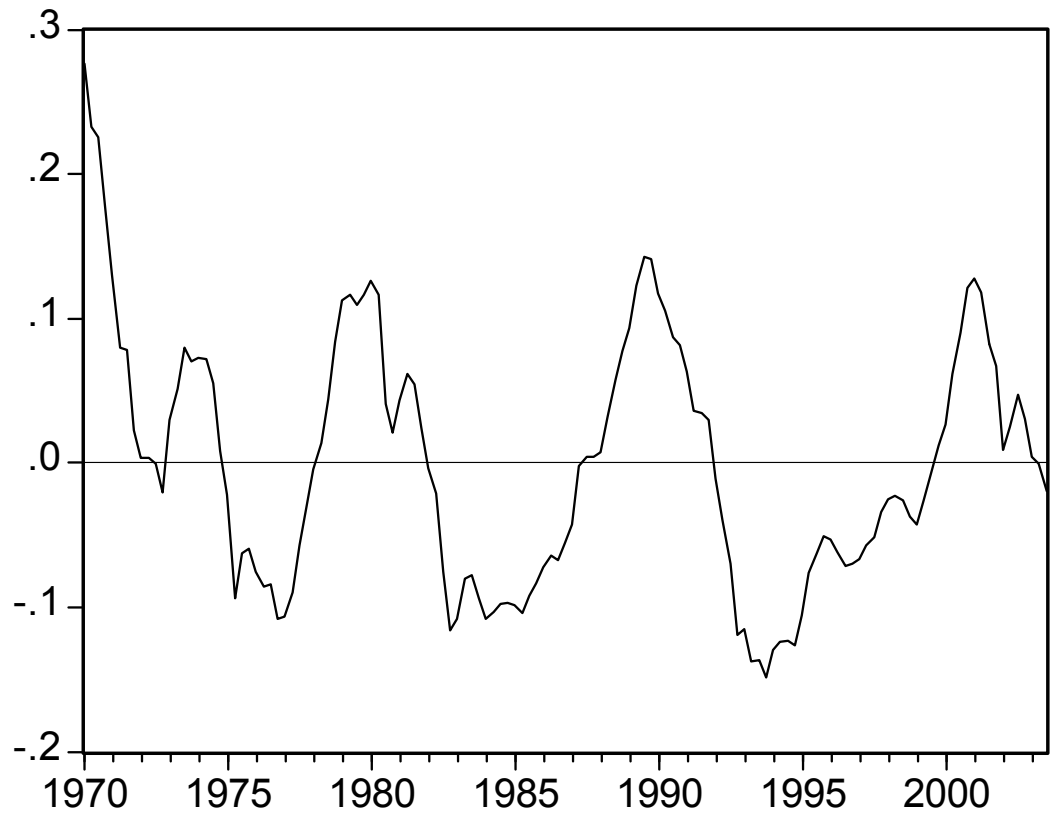

Actual and Predicted Nominal Cumulative 5-Year Growth in Land Prices

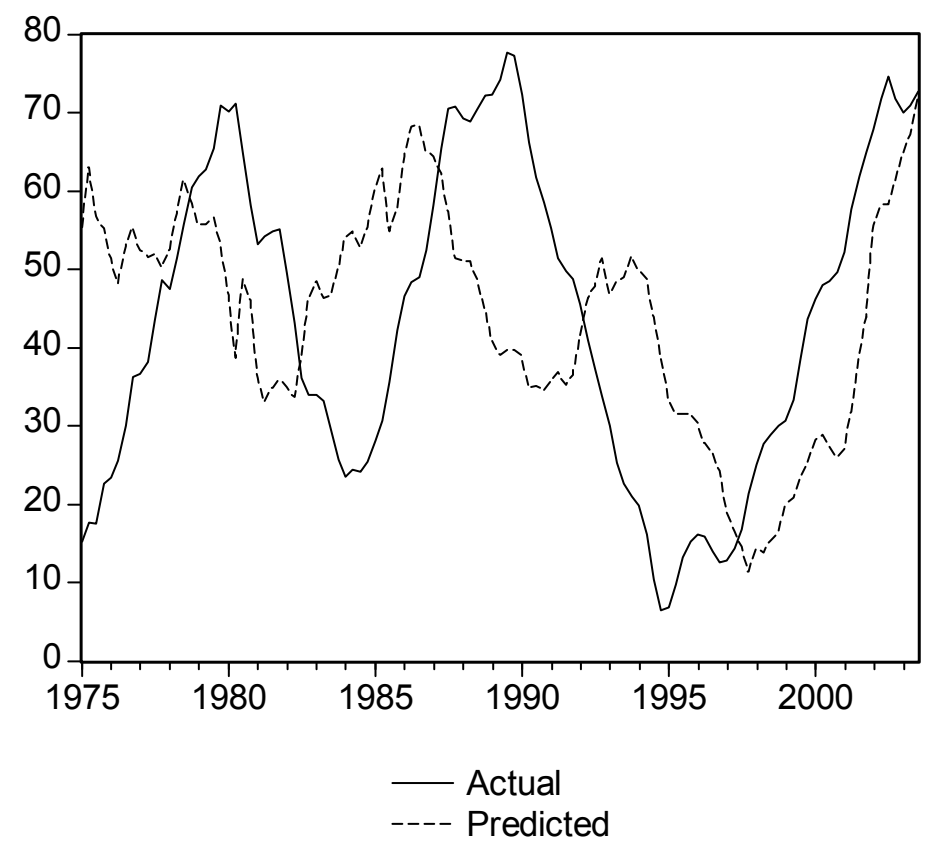


FIGURE 9

CMHPI, REPORTED AND SMOOTHED

1970:1 - 2003:3 (QUARTERLY)

Annualized Growth Rates, CMHPI (Reported and Smoothed)

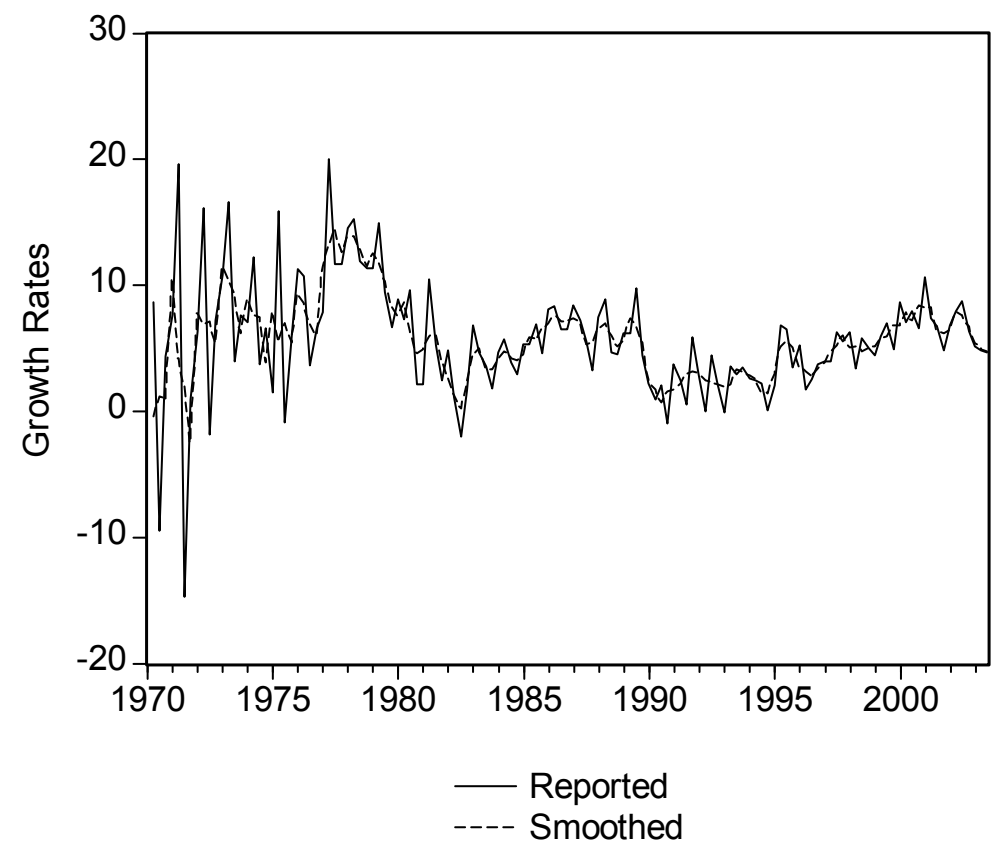

Ratio of Reported to Smoothed CMHPI

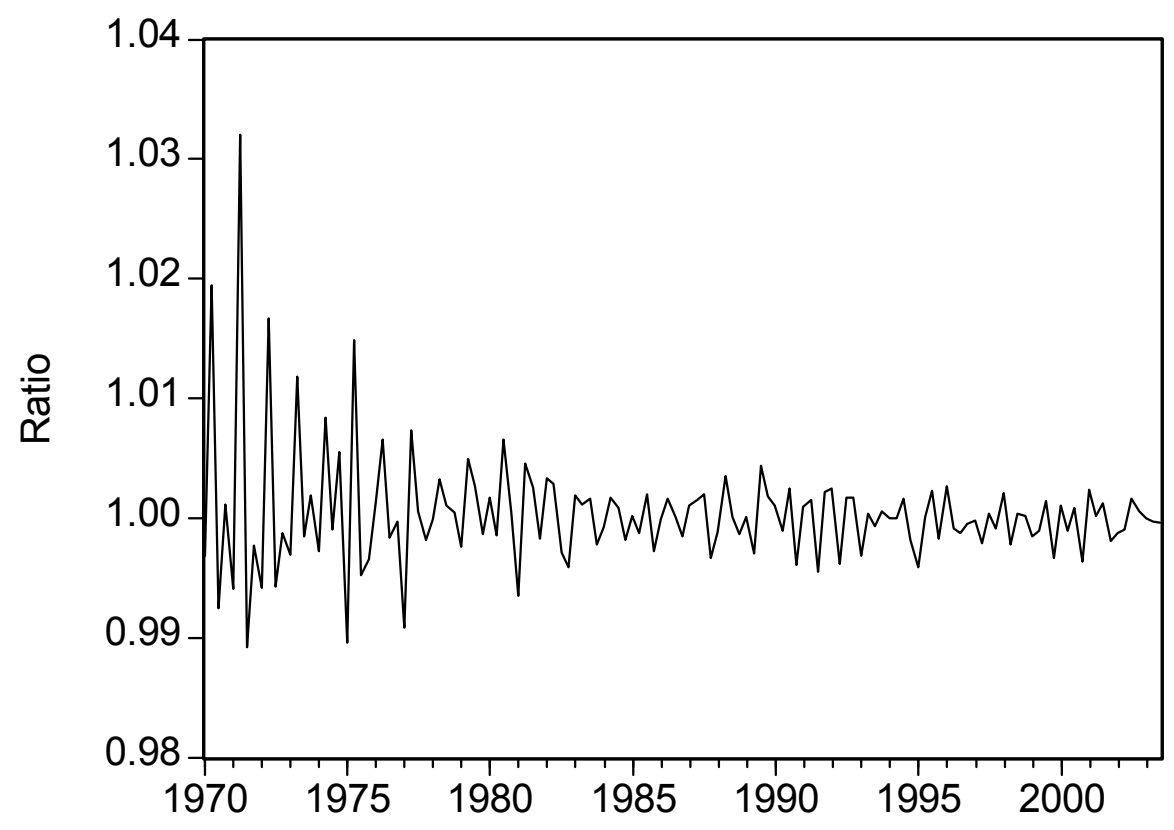


FIGURE 10

SERIES RELATED TO THE STOCK OF COMMISSIONS

ANNUAL $^{10}$

Annual Real Gross Investment in New 1-to-4 Unit Stock

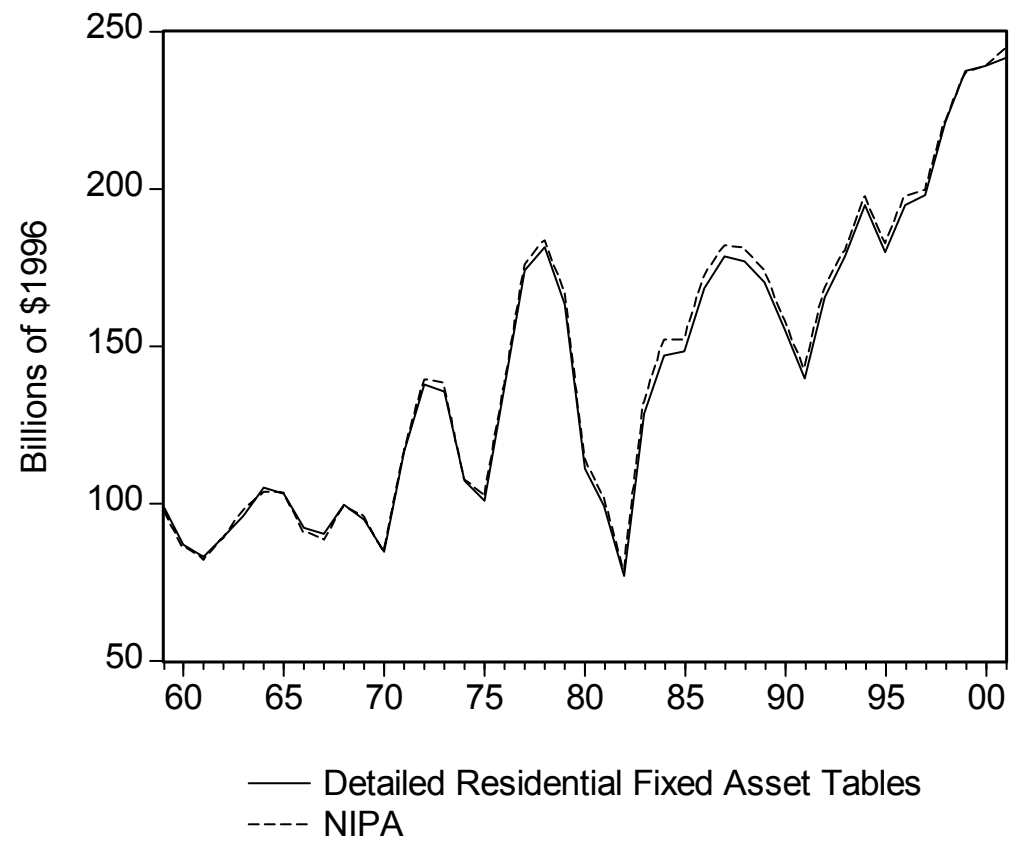

Depreciation Rate, New Stock of 1-to-4 Unit Structures

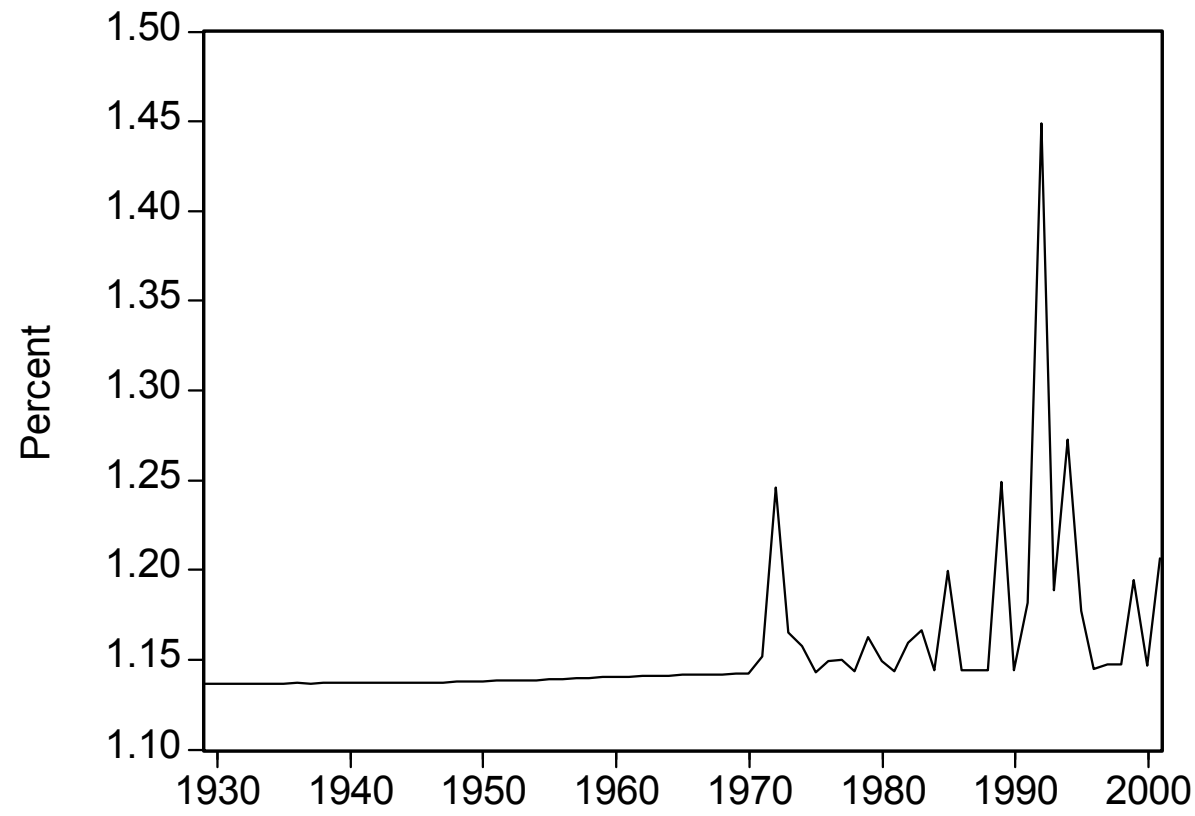

10 See text for details on construction of the depreciation rate. 
FIGURE 11

Nominal New RESIDENTIAL LAND

1970:1 - 2003:3 (QUARTERLY)

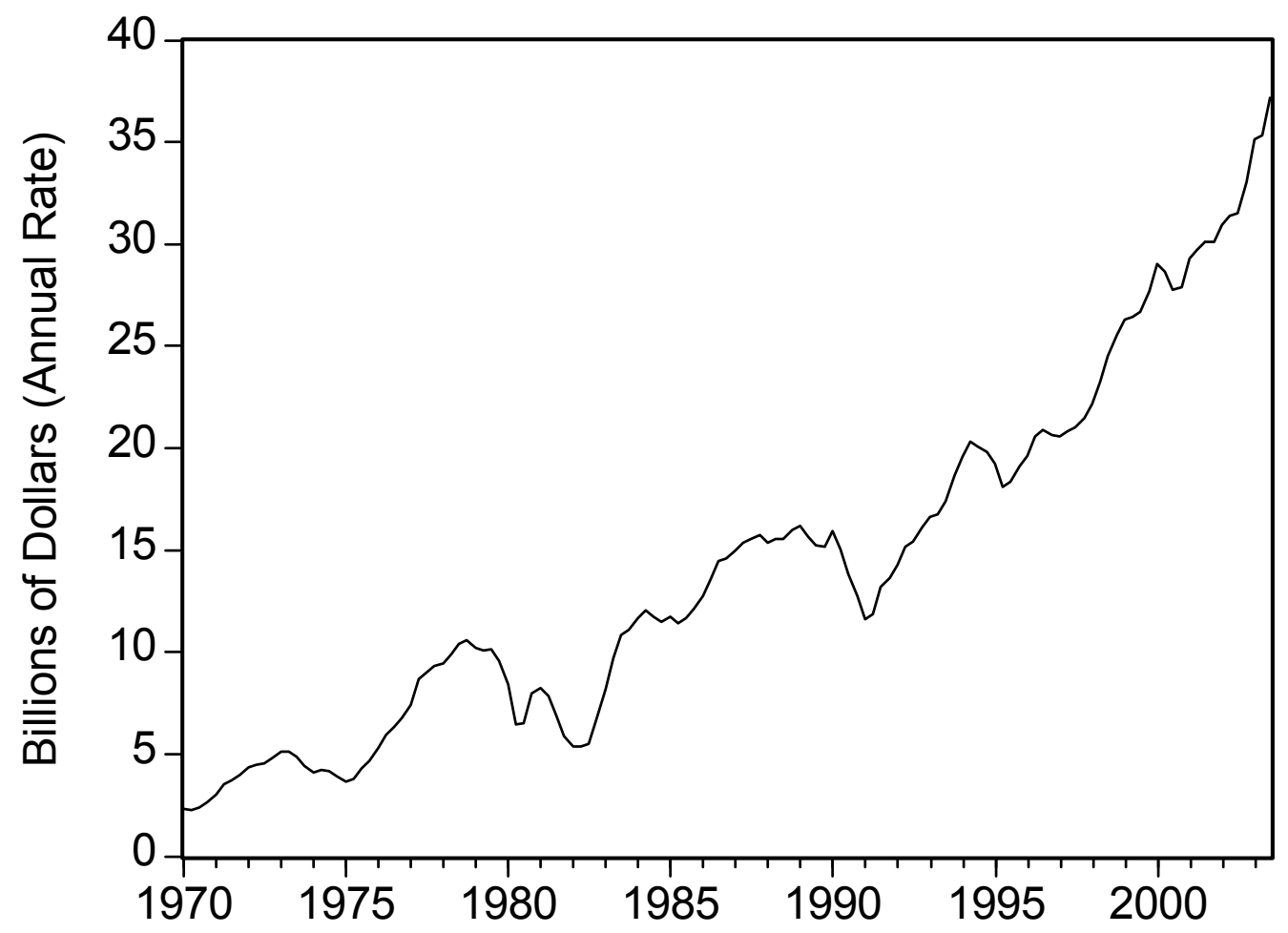


TABLE 3

DisTRIBUTION OF HOUSEHOLDS IN THE UNITED STATES

BY NUMBER OF UNITS IN STRUCTURE

ESTIMATED FROM 1\% SAMPLE FROM 2000 CENSUS

\begin{tabular}{c|ccc|c} 
& $\begin{array}{c}\text { N/A } \\
\text { (VACANT) }^{11}\end{array}$ & OWNED & RENTAL & $\begin{array}{c}\text { NUMBER OF } \\
\text { HOUSEHOLDS }\end{array}$ \\
\hline N/A & 3.9 & 81.3 & 14.8 & $2,865,033$ \\
MOBILE HOME OR TRAILER & 16.1 & 66.4 & 17.5 & $8,524,173$ \\
BOAT, TENT, VAN, OTHER & 57.9 & 32.2 & 9.9 & 273,274 \\
1-FAMILY HOUSE, DETACHED & 7.4 & 80.3 & 12.2 & $67,498,744$ \\
1-FAMILY HOUSE, ATTACHED & 8.4 & 59.6 & 32.0 & $6,211,321$ \\
2-FAMILY BUILDING & 10.5 & 23.3 & 66.2 & $4,967,510$ \\
3-4 FAMILY BUILDING & 10.6 & 12.2 & 77.1 & $5,499,852$ \\
5-9 FAMILY BUILDING & 10.7 & 9.0 & 80.3 & $5,430,474$ \\
10-19 FAMILY BUILDING & 11.2 & 8.1 & 80.7 & $4,642,033$ \\
20-49 FAMILY BUILDING & 10.9 & 10.4 & 78.7 & $3,881,027$ \\
50+ FAMILY BUILDING & 10.0 & 11.8 & 78.1 & $6,111,197$ \\
\hline \hline TUtAL & & & & $84,177,427$ \\
\hline \hline
\end{tabular}

${ }^{11}$ The Vacant, Owned, and Rental column data are percentages of the row total. 
TABLE 4

Average And Aggregate Value of Homes

BY NUMBER OF UNITS IN STRUCTURE

ESTIMATED FROM 1\% SAMPLE FROM 2000 CENSUS

\begin{tabular}{|c|c|c|c|c|c|}
\hline & \multirow{3}{*}{$\begin{array}{c}\text { OWNER }^{12} \\
\text { AVG. } \\
\text { VALUE }\end{array}$} & \multicolumn{2}{|c|}{ N/A (VACANT) } & \multicolumn{2}{|c|}{ AGGREGATE VALUE $^{13}$} \\
\hline & & РCT. & AvG. & METHOD & METHOD \\
\hline & & RESP. & VALUE & 1 & 2 \\
\hline $\mathrm{N} / \mathrm{A}$ & $\$ 174,645$ & 19.4 & $\$ 138,385$ & 499.4 & 480.9 \\
\hline MOBILE HOME OR TRAILER & $\$ 44,099$ & 12.1 & $\$ 32,863$ & 373.2 & 343.8 \\
\hline BOAT, TENT, VAN, OTHER & $\$ 49,648$ & 2.8 & $\$ 42,854$ & 13.5 & 12.3 \\
\hline 1-FAMILY HOUSE, DETACHED & $\$ 161,202$ & 19.1 & $\$ 127,108$ & $10,840.9$ & $10,427.9$ \\
\hline 1-FAMILY HOUSE, ATTACHED & $\$ 143,367$ & 19.9 & $\$ 112,731$ & 885.3 & 813.6 \\
\hline 2-FAMILY BUILDING & $\$ 173,606$ & 9.2 & $\$ 107,218$ & 849.3 & 609.5 \\
\hline 3-4 FAMILY BUILDING & $\$ 172,959$ & 5.3 & $\$ 115,914$ & 937.4 & 675.9 \\
\hline 5-9 FAMILY BUILDING & $\$ 142,438$ & 4.5 & $\$ 156,073$ & 777.2 & 840.9 \\
\hline 10-19 FAMILY BUILDING & $\$ 143,122$ & 3.1 & $\$ 146,179$ & 665.0 & 677.4 \\
\hline 20-49 FAMILY BUILDING & $\$ 168,515$ & 3.9 & $\$ 200,854$ & 659.0 & 766.5 \\
\hline 50+ FAMILY BUILDING & $\$ 195,616$ & 4.6 & $\$ 268,974$ & $1,212.2$ & $1,590.6$ \\
\hline TOTAL & & & & $17,712.4$ & $17,239.3$ \\
\hline SUBTOTAL: 1-4 UNIT & & & & $13,512.9$ & $12,526.9$ \\
\hline
\end{tabular}

\footnotetext{
${ }^{12}$ The response rate for house values for owner-occupied housing is 100 percent and for rental properties is 0 percent. In all average calculations, the top-code of one million dollars is not adjusted.

${ }_{13}$ Aggregate valuations are stated in billions of dollars. In Method 1, the missing values for vacant properties and rental units are set to the unconditional average value of the type of property. In Method 2, the missing value for vacant properties and rental units are set to the average reported value of vacant units. In both cases, the top-code of one million dollars is not changed.
} 
TABLE 5

IMPACT OF TOP-CODING ASSUMPTIONS

on Estimated Average and Aggregate Value of Homes

ESTIMATED FROM 1\% SAMPLE FROM 2000 CENSUS

\begin{tabular}{|c|c|c|c|c|c|c|c|c|}
\hline & \multicolumn{3}{|c|}{ OWNER } & \multicolumn{3}{|c|}{ N/A (VACANT) } & \multicolumn{2}{|c|}{ AGGREGATE } \\
\hline & $\begin{array}{c}\text { TOP } \\
\text { CODE } \\
\text { PCT. }^{14} \\
\end{array}$ & $\begin{array}{c}\text { AvG. } \\
\text { VALUE }\end{array}$ & $\begin{array}{c}\text { Alt. } \\
\text { AVG. } \\
\text { VALUE }^{15} \\
\end{array}$ & $\begin{array}{l}\text { TOP } \\
\text { CODE } \\
\text { PCT. } \\
\end{array}$ & $\begin{array}{c}\text { AVG. } \\
\text { VALUE }\end{array}$ & $\begin{array}{c}\text { AlT. } \\
\text { AVG. } \\
\text { VALUE } \\
\end{array}$ & $\begin{array}{c}\text { METHOD } \\
1 \mathrm{~A}\end{array}$ & $\begin{array}{c}\text { METHOD } \\
2 \mathrm{~A}\end{array}$ \\
\hline N/A & 1.2 & $\$ 174,645$ & $\$ 184,613$ & 0.7 & $\$ 138,385$ & $\$ 144,054$ & 527.8 & 507.1 \\
\hline $\begin{array}{l}\text { MOBILE } \\
\text { HOME OR } \\
\text { TRAILER }\end{array}$ & 0.1 & $\$ 44,099$ & $\mathrm{X}$ & 0.0 & $\$ 32,863$ & $\mathrm{x}$ & 373.2 & 343.8 \\
\hline $\begin{array}{l}\text { BOAT, TENT, } \\
\text { VAN, OTHER }\end{array}$ & 0.2 & $\$ 49,648$ & $\mathrm{x}$ & 0.0 & $\$ 42,854$ & $\mathrm{x}$ & 13.5 & 12.3 \\
\hline $\begin{array}{l}\text { 1-FAMILY } \\
\text { HOUSE, } \\
\text { DETACHED }\end{array}$ & 0.7 & $\$ 161,202$ & $\$ 166,703$ & 0.5 & $\$ 127,108$ & $\$ 131,404$ & $11,210.8$ & $10,783.2$ \\
\hline $\begin{array}{l}\text { 1-FAMILY } \\
\text { HOUSE, } \\
\text { ATTACHED }\end{array}$ & 0.3 & $\$ 143,367$ & $\$ 145,518$ & 0.4 & $\$ 112,731$ & $\$ 115,950$ & 898.8 & 829.6 \\
\hline $\begin{array}{l}\text { 2-FAMILY } \\
\text { BUILDING }\end{array}$ & 0.5 & $\$ 173,606$ & $\$ 177,406$ & 0.7 & $\$ 107,218$ & $\$ 112,784$ & 868.5 & 635.1 \\
\hline $\begin{array}{l}\text { 3-4 FAMILY } \\
\text { BUILDING }\end{array}$ & 1.1 & $\$ 172,959$ & $\$ 182,500$ & 0.1 & $\$ 115,914$ & $\$ 117,115$ & 987.8 & 688.1 \\
\hline $\begin{array}{l}\text { 5-9 FAMILY } \\
\text { BUILDING }\end{array}$ & 0.8 & $\$ 142,438$ & $\$ 149,182$ & 1.7 & $\$ 156,073$ & $\$ 170,265$ & 815.9 & 914.3 \\
\hline $\begin{array}{l}\text { 10-19 FAMILY } \\
\text { BUILDING }\end{array}$ & 1.5 & $\$ 143,122$ & $\$ 176,643$ & 3.7 & $\$ 146,179$ & $\$ 155,938$ & 727.8 & 812.2 \\
\hline $\begin{array}{l}\text { 20-49 FAMILY } \\
\text { BUILDING }\end{array}$ & 2.3 & $\$ 168,515$ & $\$ 187,828$ & 4.9 & $\$ 200,854$ & $\$ 241,633$ & 737.2 & 916.1 \\
\hline $\begin{array}{l}\text { 50+ FAMILY } \\
\text { BUILDING }\end{array}$ & 2.8 & $\$ 195,616$ & $\$ 218,640$ & 8.4 & $\$ 268,974$ & $\$ 338,391$ & $1,363.5$ & $1,981.3$ \\
\hline TOTAL & & & & & & & $18,524.8$ & $18,423.1$ \\
\hline $\begin{array}{l}\text { SUBTOTAL: } \\
\text { 1-4 UNIT }\end{array}$ & & & & & & & $13,965.9$ & $12,936.0$ \\
\hline
\end{tabular}

\footnotetext{
${ }^{14}$ Refers to the percentage of households with a dwelling greater in value than 1 million dollars.

${ }^{15}$ Refers to the average value when the Census top-code value of 1 million dollars is replaced with 1.83 million dollars. From the 2001 Survey of Consumer Finances, the average value of homes that are worth more than 1 million dollars is 2 million dollars; we deflate this average by 8.45 percent, the growth in the quarterly CMHPI from 2000:Q2 to 2001:Q2, to arrive at 1.83 million. The top-code of 1 million is not adjusted for mobile homes or boats.
} 
FIGURE 12

REAL STOCK OF LAND

COMPUTED WITH FLOW OF FUNDS DATA

1970:Q1 - 2003:Q3 (QUARTERLY)

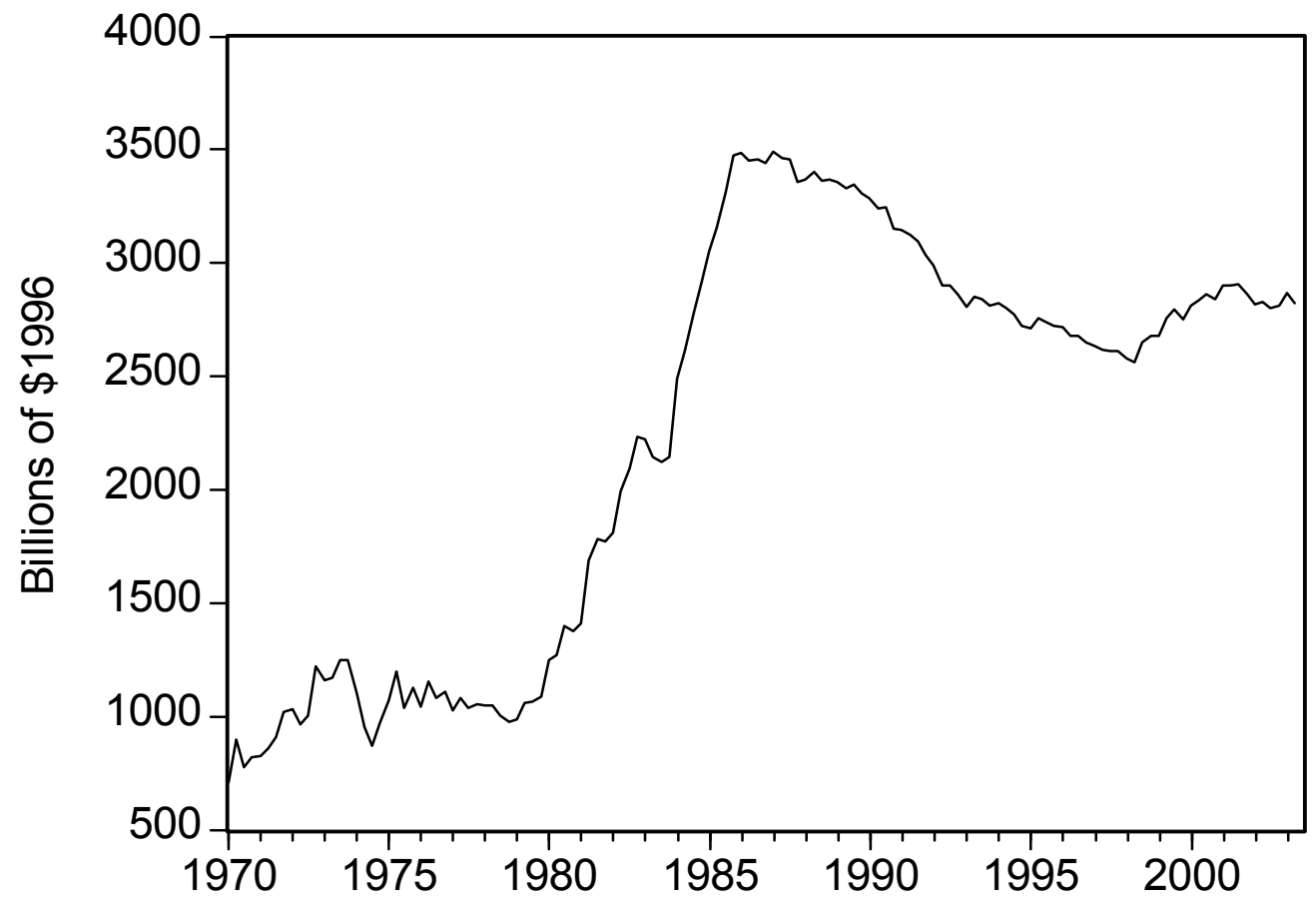


FIGURE 13

PRICE AND QuANTITY OF LAND, BASELINE AND ALTERNATIVE \# $1^{16}$

1970:1 - 2003:3 (QUARTERLY)
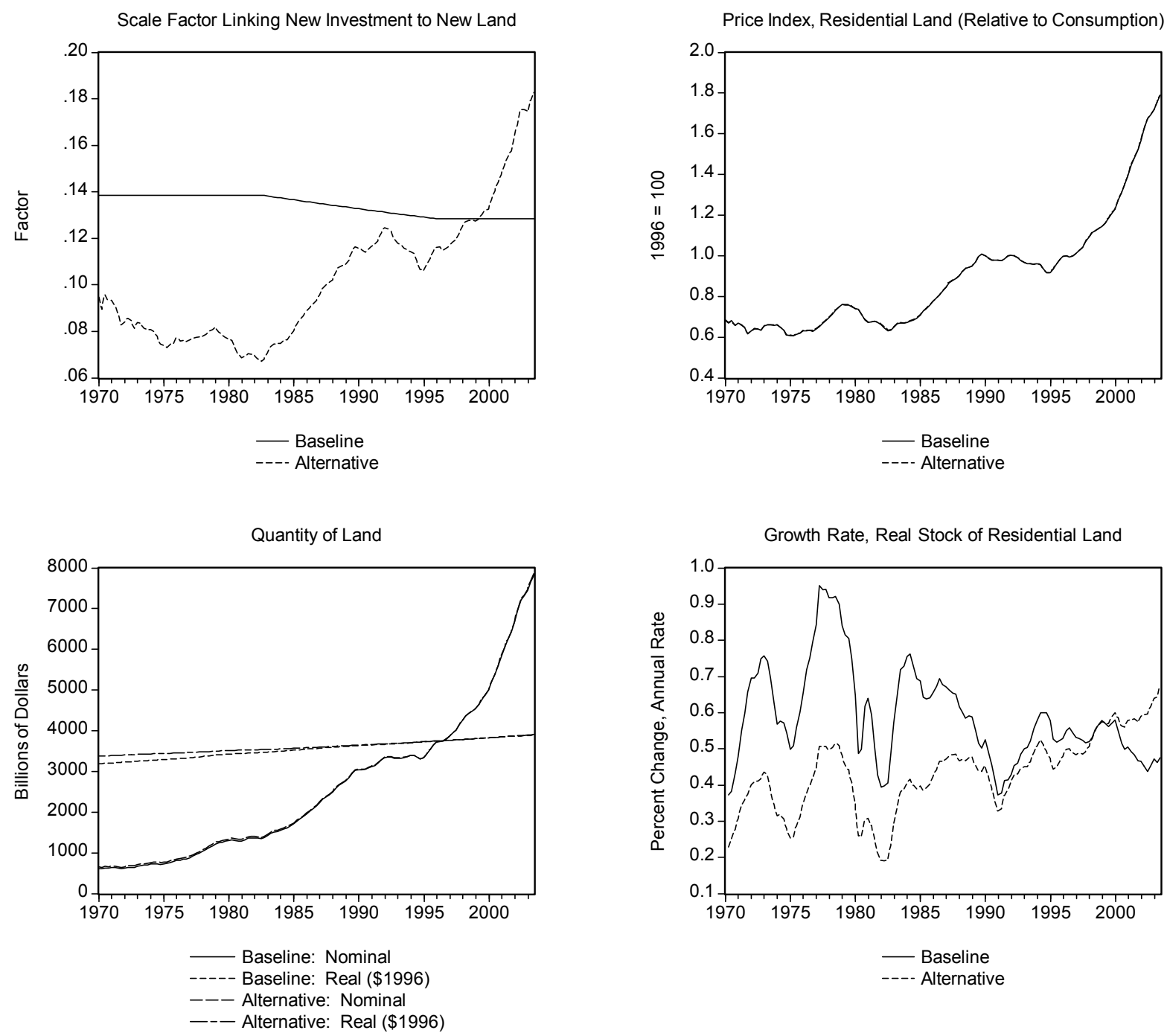

16 In this alternative specification, we specify that real units of new land and real units of new structures are combined in fixed proportion when assembling real new units of housing. In the baseline specification, we assume that nominal expenditure shares on land and structures are approximately fixed. See the text for details. 


\section{FIGURE 14}

Price AND QUANTITY of LAND, BASELINE AND ALTERnATIVE \#2 ${ }^{17}$

1970:1 - 2003:3 (QUARTERLY)
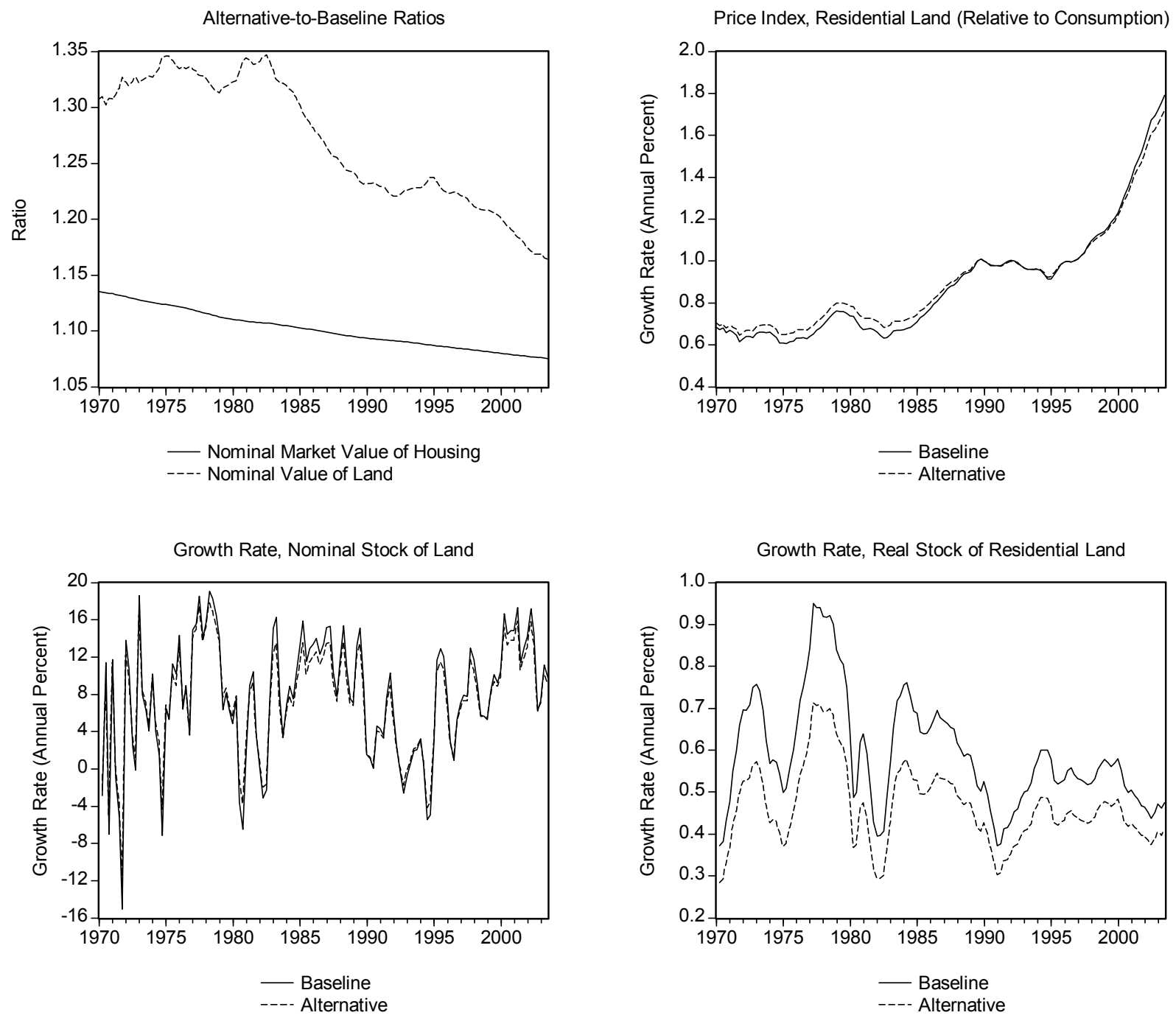

17 In this alternative specification, we specify that the market value of the residential housing stock in 2000:Q2 is \$13.97 trillion (rather than $\$ 12.94$ billion as in the baseline specification). See the text for details. 